ERIC RIBEIRO PICCELLI

\title{
NOVOS PLANOS, VELHOS PROBLEMAS \\ O POSITIVISMO JURÍDICO DE SCOTT SHAPIRO
}

Dissertação de Mestrado

Orientador: Professor Titular Dr. Ronaldo Porto Macedo Júnior

UNIVERSIDADE DE SÃO PAULO

FACULDADE DE DIREITO

SÃO PAULO-SP

2018 



\title{
NOVOS PLANOS, VELHOS PROBLEMAS \\ O POSITIVISMO JURÍDICO DE SCOTT SHAPIRO
}

\begin{abstract}
Dissertação apresentada à Banca Examinadora do Programa de Pós-Graduação em Direito, da Faculdade de Direito da Universidade de São Paulo, como exigência parcial para obtenção do título de Mestre em Direito, na área de concentração denominada Filosofia e Teoria Geral do Direito, sob orientação do Professor Titular Dr. Ronaldo Porto Macedo Júnior.
\end{abstract}

UNIVERSIDADE DE SÃO PAULO

FACULDADE DE DIREITO

SÃO PAULO-SP

2018 
Catalogação da Publicação

Serviço de Biblioteca e Documentação

Faculdade de Direito da Universidade de Sẩo Paulo

Piccelli, Eric Ribeiro

Novos Planos, Velhos Problemas: o positivismo jurídico de Scott Shapiro / Eric Ribeiro Piccelli ; orientador Ronaldo Porto Macedo Junior - São Paulo,

2018.

$150 \mathrm{p}$.

Dissertação (Mestrado - Programa de Pós-Graduação em Filosofia do Direito e Teoria Geral do Direito) - Faculdade de Direito, Universidade de São Paulo, 2018.

1. Positivismo Jurídico. 2. Direito como Planejamento. 3. Tese da Separação. 4 Normatividade. 5. Desacordos Teóricos. I. Porto Macedo Junior, Ronaldo, orient. II. Titulo. 
Nome: PICCELLI, Eric Ribeiro

Título: Novos planos, velhos problemas: o positivismo jurídico de Scott Shapiro

Dissertação apresentada à Faculdade de Direito da Universidade de São Paulo como exigência parcial para obtenção do título de Mestre em Direito.

Aprovado em:

Banca Examinadora:

Prof. Dr. Instituição:

Julgamento: Assinatura:

Prof. Dr. Instituição:

Julgamento:

Assinatura:

Prof. Dr. Instituição:

Julgamento: Assinatura: 



\section{AGRADECIMENTOS}

Sou profundamente grato ao Professor Ronaldo Porto Macedo Junior pela oportunidade que me deu de receber sua orientação e de participar do Programa de PósGraduação em Direito da FADUSP. Antes desta jornada eu o admirava apenas por suas brilhantes credenciais acadêmicas; depois dela vi essa admiração ser eternamente qualificada por suas ainda mais brilhantes credenciais humanas.

Agradeço aos Professores Thomas da Rosa de Bustamante e Rafael Mafei Rabelo Queiroz, tanto pelas excelentes contribuições que me deram ao participarem de meu exame de qualificação quanto pela honra que me concederam ao comporem a banca perante a qual apresentei minha defesa; à Profa. Clarissa Piterman Gross, por aceitar ser integrante daquele mesmo colegiado, abrilhantado por sua presença; ao Prof. José Reinaldo de Lima Lopes, pela enriquecedora convivência durante o seminário de Hermenêutica e Razão Prática, a qual me trouxe dividendos acadêmicos e humanos que ainda não terminei de colher; ao Prof. Leonardo Gomes Penteado Rosa, pela longa conversa às vésperas de minha qualificação e pela gentileza com que me ajudou naquele momento tão importante e de tantas dúvidas; ao Prof. Pablo Antonio Lago, pelas observações que muito me esclareceram e pela assistência quando foi necessário requerer a prorrogação do prazo de que eu dispunha para depositar este trabalho; aos colegas de curso e de monitorias, bem como a Daniel Peixoto Murata, Octavio Sampaio de Moura Azevedo e aos demais orientandos do Prof. Ronaldo, cujas contribuições são muito numerosas para citar aqui; aos servidores e ex-servidores da Secretaria da Pós-Graduação da FADUSP com quem tive contato no decorrer dos últimos quatro anos, especialmente a Dona Maria de Fátima Silva Cortinhal, que gentilmente me socorreu diante de uma grande dificuldade logística, viabilizando a realização de meu exame de qualificação, a Mario Paulino, pelas iluminadoras observações feitas quando do protocolo de meu primeiro projeto de pesquisa, e a Alexandre de Alencar Banho, pela diligência no atendimento de requerimentos e disponibilidade na resolução de dúvidas; a Alexandra Elbakyan, pela incansável defesa da ideia de que o conhecimento deve ser livremente difundido e compartilhado. 
Agradeço a André Boiani e Azevedo pela amizade, pelo incentivo e pela complacência ao longo dos últimos anos, esperando um dia atingir o mesmo patamar de seriedade, de dedicação e de capacidade intelectual de que ele tem sido um exemplo diário; a Lucas Ribeiro do Prado, pela amizade, pelo infindável bom humor, e pela paciência com a qual encarou minha entrega à pesquisa; a Solange Maria Poço Tsuha e a Givaldo Galdino de Souza, cuja ajuda cotidiana tornou tudo mais factível.

Agradeço a Leandro Augusto Rodrigues pelo incentivo e pelo auxílio durante o processo seletivo para o Programa de Mestrado; a Anderson Navarro, Paulo Levi Pereira da Silva e Thiago Brandão pela amizade verdadeira de sempre, cujo valor não pode ser expresso em palavras; a Celso Prado e a Marcos Augusto Maranhão pela compreensão nos períodos em que minha ausência foi necessária; aos diversos amigos e irmãos que me animaram a chegar ao fim deste trajeto mesmo sem entenderem bem o que ele significava.

Agradeço à minha família pelo amor e pela paciência infindáveis que tem me dispensado; a Luciana, amor e inspiração da minha vida, por ser o meu porto seguro de todos os dias, por não medir sacrifícios para me ajudar desde o primeiro segundo da caminhada, e por me despertar para a atividade acadêmica; a Juliana, meu tesouro, por fazer todos os meus dias felizes e tornar todo e qualquer esforço digno de ser posto em prática; aos meus pais, pela vida, pela formação, pelo exemplo, pelo sangue nas veias, pelo sentimento no coração e pela esperança na alma; a Bruna, que mesmo à distância me apoiou em tudo e se alegrou comigo; aos meus sogros, pelo acolhimento carinhoso e pela alegria que me dão ao me tratarem e amarem como filho; ao tio Carlos e à tia Júlia, que de tantas vitórias participaram, e que por isso vencem comigo; e a Paulo Sérgio Ribeiro Sobrinho, cujas conquistas comemoro mais do que as minhas próprias, pelo constante contato, pelo crescimento conjunto e pelos frequentes debates (também) acadêmicos.

Acima de tudo agradeço a Deus, diante de quem sou um devedor eterno. 
Para Luciana e Juliana. 

A man said to the universe:

"Sir, I exist!"

"However," replied the universe,

"The fact has not created in me

A sense of obligation."

(Stephen Crane) 



\section{RESUMO}

PICCELLI, Eric Ribeiro. Novos planos, velhos problemas. O positivismo jurídico de Scott Shapiro. 150 f. Mestrado. Faculdade de Direito, Universidade de São Paulo, São Paulo, 2018.

Desde a publicação de Legality a teoria do direito de Scott Shapiro tem estado no centro do debate contemporâneo em filosofia do direito. Essa teoria é construída em redor das afirmações de que (1) normas jurídicas são planos e de que (2) a atividade jurídica é uma atividade de planejamento. Neste trabalho tento avaliar criticamente a sua obra, usando a ideia de separação entre direito e moral, também conhecida como tese da separação, como minha lente conceitual. Exploro as consequências da aliança de Shapiro a essa ideia em dois níveis teóricos diferentes. O primeiro é o da fundação do direito, enquanto o segundo é o da prática jurídica. Com relação ao primeiro sustento que a aposta de Shapiro na particular concepção de racionalidade defendida por Michael Bratman não o aparelha com as ferramentas filosóficas de que ele necessita para explicar adequadamente a normatividade do direito. Observo que o dilema que ele procura solucionar é de ordem moral, e como tal só pode ser superado por deliberação moral - deliberação de tipo incompatível com a noção de que o direito e a moral constituem-se em dois domínios normativos separados. Essa particular afirmação descarta o convencionalismo como teoria sólida da normatividade do direito, mesmo em sua sofisticada forma shapiriana. Já quanto ao segundo, postulo que uma boa teoria do direito deve explicar os fenômenos que Ronald Dworkin chamou de desacordos teóricos, e que o positivismo de Shapiro, a despeito de sua sofisticação, não pode fazê-lo precisamente em função de sua insistência na tese da separação. Concluo que a única maneira de salvar a teoria de Shapiro é modificando seus compromissos fundamentais de maneira a transformá-la em uma instância de positivismo normativo.

Palavras-chave: Scott Shapiro; positivismo jurídico; tese da separação; Michael Bratman; planejamento; convencionalismo; normatividade; desacordos teóricos; Ronald Dworkin; positivismo normativo. 


\begin{abstract}
PICCELLI, Eric Ribeiro. New plans, old problems. The legal positivism of Scott Shapiro. 150 p. Master’s Degree. Faculty of Law, University of São Paulo, São Paulo, 2018.

Since the publishing of Legality, Scott Shapiro's theory of law has been at the center of current jurisprudential debates. That theory is constructed around the claims that (1) laws are plans and that (2) legal activity is an activity of social planning. In this work I try to assess his oeuvre critically, using the idea of separation between law and morality, also known as separation thesis, as my conceptual lens. I explore the consequences of Shapiro's allegiance to that idea in two different theoretical levels. The first one is that of the foundations of law, while the second is that of legal practice. With regards to the first, I contend that Shapiro's reliance on the particular conception of rationality that goes along with planning, and that is defended by Michael Bratman, does not provide him with the philosophical tools he needs to give an adequate account of law's normativity. I point out that the puzzle he aims to solve is a moral one, and as such can only be solved through moral reasoning - reasoning of a kind that is not compatible with the notion that law and morality constitute two separate normative domains. That particular contention rules out conventionalism as a sound theory of law's normativity, even in its sophisticated Shapirian form. As for the second, I argue that a good theory of law must explain the phenomena dubbed by Ronald Dworkin as theoretical disagreements, and that Shapiro's positivism, in spite of its sophistication, cannot do that precisely because of its insistence on the separation thesis. I conclude that the only way to salvage Shapiro's theory is by amending its core commitments in order to transform it in an instance of normative positivism.
\end{abstract}

Keywords: Scott Shapiro; legal positivism; separation thesis; Michael Bratman; planning; conventionalism; normativity; theoretical disagreements; Ronald Dworkin; normative positivism. 


\section{SUMÁRIO}

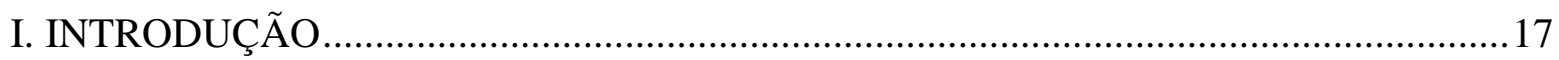

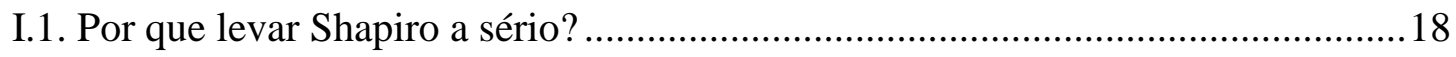

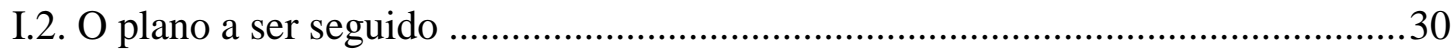

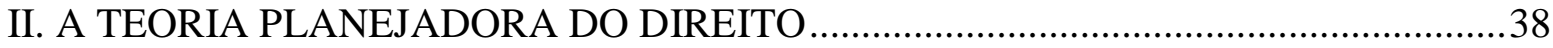

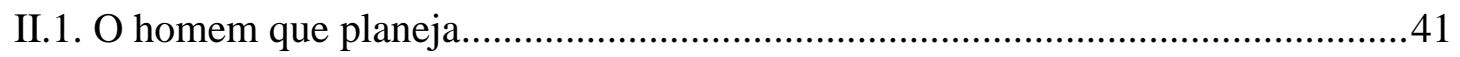

II.2. O direito como atividade de planejamento....................................................45

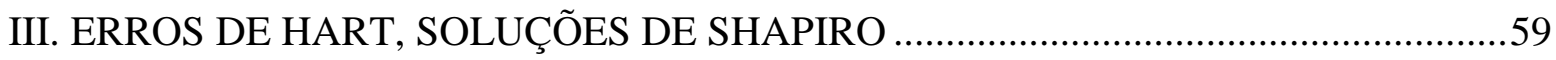

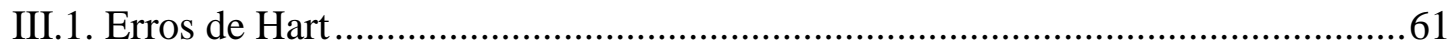

III.2. A solução de Shapiro para o Dilema da Possibilidade .......................................63

III.3. A solução de Shapiro para o Desafio de Hume ...................................................73

IV. O PLANO-MESTRE DE SHAPIRO E O CONVENCIONALISMO ..........................76

IV.1. Regra de reconhecimento, razões e convenções ................................................78

IV.2. O Dilema da Possibilidade como uma questão moral ........................................80

IV.3. A morte e a morte da tese da separação...............................................................83

V. A PRÁTICA DOS PLANOS E OS DESACORDOS TEÓRICOS …..............................96

V.1. Introdução à natureza do argumento .................................................................97

V.2. Dworkin e o argumento dos desacordos teóricos ............................................. 101

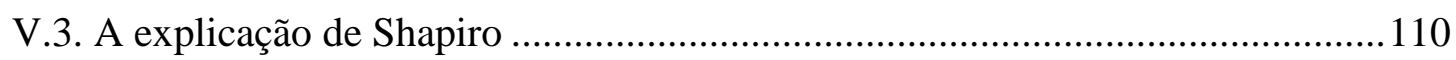

V.4. A persistência do problema............................................................................. 122

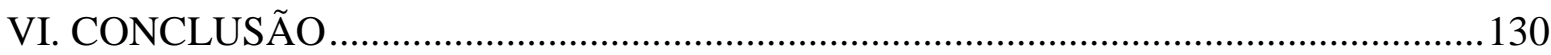

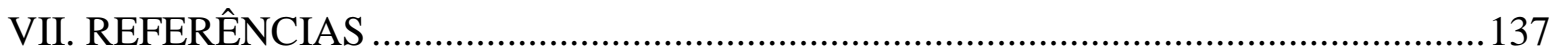





\title{
I. INTRODUÇÃO
}

\author{
Your absence has gone through me \\ Like thread through a needle. \\ Everything I do is stitched with its color.
}

Em 2011 um jovem teórico norte-americano publicou um trabalho de muito fôlego em que procurou apresentar uma nova vertente de positivismo jurídico exclusivista. Scott J. Shapiro é esse teórico e Legality ${ }^{2}$ é sua obra principal. Sua peculiar teoria parte da concepção de que o homem é um agente planejador e afirma (1) que o direito é um sofisticado instrumento de planejamento social, (2) que as normas jurídicas são planos, e (3) que a determinação da existência e do conteúdo do direito depende apenas da análise sociológica dos fatos relevantes, sem que a moral participe dessa operação. Ele também articula particulares soluções para os problemas centrais da filosofia do direito, todas de algum modo dependentes da, ou vinculadas à, tese da separação entre o direito e a moral.

Nesta dissertação identifico dois níveis em que a tese da separação pode ser situada no empreendimento teórico de Shapiro, notadamente (1) o da fundação do direito e (2) o da prática jurídica, e em seguida discuto esse novo positivismo nesses dois contextos.

Quanto ao primeiro descrevo como o autor tenta resolver o problema da autoridade (ou da normatividade) do direito, relativamente aos oficiais do sistema jurídico, reconstruindo a regra de reconhecimento de Hart, abandonando a ideia hartiana de ponto de vista interno e apresentando um novo tipo de convencionalismo fundado na racionalidade instrumental do planejamento. Afirmo que sua teoria não se sustenta porque não é capaz de explicar, sem apelo à moral, como o direito confere razões para agir a esses oficiais.

No que se diz respeito ao segundo mostro como Shapiro procura elucidar o fenômeno dos desacordos teóricos presentes em nossas práticas jurídicas com a assertiva de que eles se referem a controvérsias acerca de metodologias interpretativas, as quais podem ser determinadas apenas por fatos sociais, novamente sem demandar ou comportar deliberação moral, e sustento que sua solução não se harmoniza com a racionalidade dos

\footnotetext{
${ }^{1}$ MERWIN, W. S. The second four books of poems .Port Townsend, WA: Copper Canyon Press, 1993, p. 15.

${ }^{2}$ SHAPIRO, Scott. Legality. London/Cambridge: The Belknap Press of Harvard University Press, 2011.
} 
juízes. Estes, ao decidirem a partir de razões jurídicas referidas a valores, e não apenas ao direito positivado, mostram que não estão comprometidos com a lógica dos planos.

Minha conclusão é a de que é mal sucedida a tentativa de salvar a tese da separação, e com ela o positivismo jurídico hartiano, a partir do recurso aos planos e à racionalidade do planejamento, o que acaba por demonstrar que devemos abandonar a insistência dos positivistas em seus termos.

Nas seções seguintes, a título de introdução, expando essa descrição e relato em maiores detalhes o que farei neste trabalho e como desenvolverei a discussão aqui sumarizada. Antes disso esclareço por quais motivos considero que a obra de Shapiro merece ser estudada e discutida.

\section{Por que levar Shapiro a sério?}

Scott J. Shapiro é um jovem professor da Yale University. Ele é um positivista exclusivista e nessa capacidade tem sido participante ativo das mais atuais discussões concernentes à filosofia do direito de tradição Anglo-Saxã. Em especial, e apesar de entender que a disciplina deve se expandir para além dessa espécie de preocupação ${ }^{3}$, ele tem dado relevantes contribuições para a compreensão das questões inicialmente suscitadas naquele que ficou conhecido como o debate Hart-Dworkin.

Após publicar alguns artigos que tratavam dos pontos centrais ${ }^{4}$ e da própria natureza desse debate - que ele procurou apresentar de modo sucinto àqueles não iniciados em seus mais importantes temas, destacando que o principal foco da discórdia, em sua visão, estava em saber se fatos morais determinam ou não a existência e o conteúdo do

\footnotetext{
${ }^{3}$ PLUNKETT, David, SHAPIRO, Scott. Law, morality, and everything else: general jurisprudence as a branch of metanormative inquiry. Ethics, 128, October 2017, pp. 37-68.

${ }^{4}$ SHAPIRO, Scott. On Hart's way out. Legal Theory. Volume 4, Issue 4, December 1998, pp. 469-507. SHAPIRO, Scott. Was inclusive legal positivism found on a mistake? Ratio Juris, Volume 22, Number 3, September 1999, pp. 326-338; SHAPIRO, Scott. Authority. In: COLEMAN, Jules; SHAPIRO, Scott. The Oxford handbook of jurisprudence \& philosophy of law. Oxford: Oxford University Press, 2002, pp. 383439; SHAPIRO, Scott. What is the internal point of view? Fordham Law Review, Volume 75, Issue 3, 2006, pp. 1157-1170; SHAPIRO, Scott. What is the rule of recognition (and does it exist)? In: ADLER, Matthew D., HIMMA, Kenneth Einar (editors). The rule of recognition and the U.S. Constitution. Oxford: Oxford University Press, 2009, pp. 235-268.
} 
direito $^{5}$-, Shapiro ofereceu à comunidade jurídica sua particular teoria do direito, exposta no livro Legality.

A obra despertou a atenção de grandes players da filosofia do direito contemporânea ${ }^{6}$. Numerosos artigos foram produzidos sobre o livro, que foi rapidamente

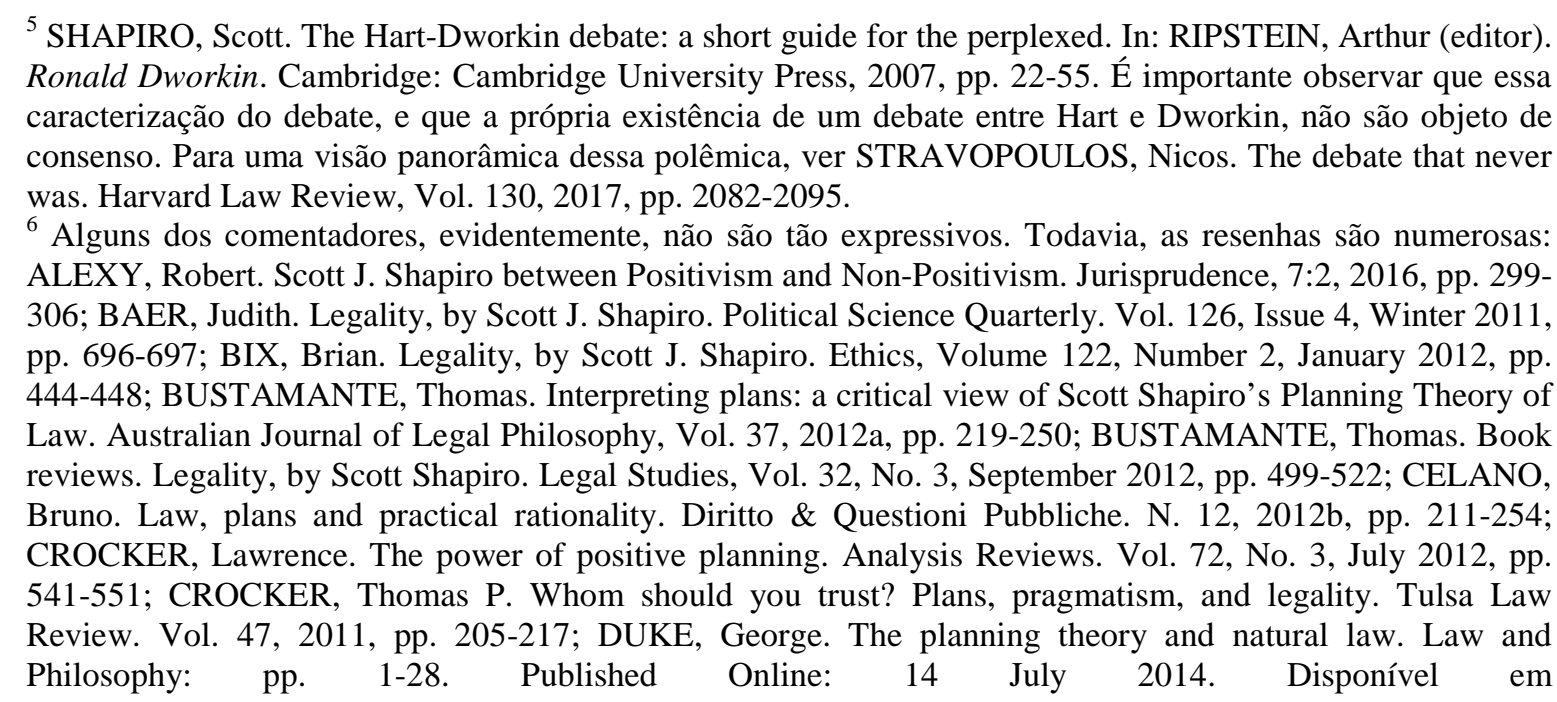
<http://link.springer.com/article/10.1007/s10982-014-9213-x>. Acesso em 15/11/2014; DYZENHAUS, David. Legality without the rule of law? Scot Shapiro on wicked legal systems. Critical notice: Legality, by Scott Shapiro. Canadian Journal of Law and Jurisprudence. Vol. XXV. No. 1. January 2012, pp. 183-200. EDMUNDSON, William. Shmegality. Georgia State University College of Law. Legal Studies Research Paper No. 2012-02. 2011. Disponível em 〈http://ssrn.com/abstract=1835746〉. Acesso em 05/05/2014; FARRELL, Ian P. On the value of jurisprudence. Legality, by Scott J. Shapiro. Texas Law Review. Vol. 90, 2011, pp. 187-224; GARDNER, John; MACKLEM, Timothy. Scott J. Shapiro. Legality. Notre Dame Philosophical Reviews. 2011. Disponível em <http://ndpr.nd.edu/news/27609-legality/>. Acesso em 27/03/2014; GREEN, Michael S. On Hart's category mistake. Legal Theory. Vol. 19, 2013, pp. 347-369; GUEST, Stephen. GLOP, The moral aim of the law and trusting judges. Analysis Reviews, Vol. 72, Number 3, July 2012, pp. 552-563. HERSHOVITZ, Scott. The model of plans and the prospects for positivism. Public Law and Legal Theory Research Series. Paper no. 354. September 2013. Disponível em < http://ssrn.com/abstract=2322457>, Acesso em 16/09/2014; MURPHY, Mark C. Book review. Legality, by Scott J. Shapiro. Law and Philosophy, Number 30, 2011, pp. 369-375; MURPHY, Mark C. No more fresh starts. Analysis Reviews. Vol. 72, No. 3, 2012, pp. 563-573; PULIDO, Carlos Bernal. Austin, Hart e Shapiro: três concepções sobre o direito como entidade fundada em uma prática social. Tradução de Thomas da Rosa de Bustamante. Revista Brasileira de Estudos Políticos. No. 307, Julho/Dezembro de 2013, pp. 43-98; RIPSTEIN, Arthur. Self-certification and the moral aims of the law. Critical notice: Legality, by Scott Shapiro. Canadian Journal of Law and Jurisprudence, Vol. XXV, No. 1, January 2012, pp. 201-2017; RODRIGUEZ-BLANCO, Veronica. The moral puzzle of legal authority. A commentary on Shapiro's Planning Theory of Law. In: BERTEA, Stefano; PAVLAKOS, George (editors). New essays on the normativity of law. Oxford and Portland, Oregon, 2011, pp. 86-106; ROSATI, Connie S. Normativity and the Planning Theory of Law. Jurisprudence, 7:2, 2016, pp. 307-324; SCHAUER, Frederick. The best laid plans. Legality, by Scott J. Shapiro. The Yale Law Journal. No. 120, 2010, pp. 586-621; SIMMONDS, Nigel E. The logic of planning and the aim of the law. University of Toronto Law Journal, Vol. 62, No. 2, Spring 2012, pp. 255-276; YAFFE, Gideon. Book review: Legality. Philosophical Review, Vol. 121, No. 3, 2012, pp. 451474; WALDRON, Jeremy. Planning for legality. Michigan Law Review. Vol. 109, April 2011, pp. 883-902. Também no Brasil a obra despertou interesse, cf. BUSTAMANTE, Thomas; CUNHA, Mirlir. Muito além do plano: objeções à visão de direito de Scott Shapiro. 2013. Disponível em <http://www.publicadireito.com.br/artigos/?cod=8386fa112ba70c3f>, Acesso em 20/04/2014; MACEDO JUNIOR, Ronaldo Porto. O direito em desacordo. O debate entre o interpretativismo e o convencionalismo jurídico. 2013. 247 f. Tese (Concurso de Professor Titular) - Faculdade de Direito, Universidade de São Paulo, São Paulo, 2013a; MACEDO JUNIOR, Ronaldo Porto. Do xadrez à cortesia. São Paulo: Saraiva, 
traduzido ao Espanhol ${ }^{7}$ e ao Chinês $^{8}$, e que deu ensejo à edição, pela prestigiosa editora Springer, de um volume inteiramente dedicado a discuti-1o ${ }^{9}$. Os editores do tradicional periódico Analysis Reviews também se preocuparam em promover um simpósio ${ }^{10}$ para discussão de Legality, do qual o próprio Shapiro tomou parte, primeiro apresentando os aspectos principais de sua obra, e depois respondendo a alguns de seus críticos.

Por que tanto interesse em Shapiro, afinal? Ele não seria apenas mais um dentre os inúmeros comentadores das obras de H. L. A. Hart e Ronald Dworkin - e um dos mais inexpressivos dentre eles, dada sua entrada tardia na discussão que toma por ponto de partida as teorias desses dois autores, e que foi iniciada no final da década de 1960 ?

Um primeiro mérito de Legality, ao meu ver, é o de ter sido apresentado como uma obra clara e didática, em que as questões fulcrais da filosofia do direito do presente são expostas de forma sistemática e razoavelmente precisa. O que Shapiro nos entrega é um livro declaradamente positivista que pretende, dentre outras coisas, cumprir o papel de mapa do atual estado da disciplina, e que parece fazê-lo adequadamente. As resenhas da obra, em geral críticas quanto às especificidades da teoria shapiriana, são praticamente unânimes em reconhecer essa sua virtude.

O trabalho do autor também desperta interesse porque no tempo atual raramente surgem novas teorias do direito ${ }^{11}$. Shapiro não se limita a comentar e a tentar incrementar as posições dos teóricos consagrados em seu domínio de estudo, mas se esforça por desenvolver seu peculiar sistema de pensamento. É bem verdade que esse sistema se mostra em grande medida tributário das inovações que Michael Bratman introduziu no campo da filosofia da ação, as quais já haviam sido incorporadas à filosofia do direito por Jules Coleman ${ }^{12}$. Mesmo assim, como ficará mais claro a seguir, Shapiro de algum modo se descola das concepções positivistas mais tradicionais, pelo que sua produção teórica

2013b; NEIVA, Horário Lopes Mousinho. Teoria do direito e análise conceitual: uma crítica à metodologia de Scott J. Shapiro. Revista da Faculdade de Direito da UFMG, Belo Horizonte, n. 65, jul./dez. 2014, pp. 261-284. Já há até um teórico brasileiro que se apresenta como, em alguma medida, shapiriano (TORRANO, Bruno. Do fato à legalidade. Introdução à teoria analítica do direito. Rio de Janeiro: Lumen Juris, 2014).

${ }^{7}$ SHAPIRO, Scott. 2014.

${ }^{8}$ SHAPIRO, Scott. 合法性. China: China Legal Publishing House, 2016.

9 CANALE, Damiano; TUZET, Giovanni (Eds). The planning theory of law. A critical reading. Dordrecht/Heidelberg/New York/London: Springer, 2013.

${ }^{10}$ Book Symposium. Legality, by Scott Shapiro. Analysis Reviews, Vol. 72, Number 3, July 2012.

${ }^{11}$ Independentemente das discussões que possam existir em torno de eventuais distinções entre as expressões filosofia do direito e teoria do direito, aqui as emprego como sinônimas uma da outra.

${ }_{12}$ COLEMAN, Jules. The practice of principle: in defense of a pragmatist approach to legal theory. Oxford: Oxford University, 2001. 
merece ser tratada sob a rubrica de um novo positivismo. O próprio Coleman o qualifica como autor de uma das mais sofisticadas defesas do positivismo exclusivista hoje disponíveis, somente comparável em sofisticação àquela formulada por Joseph $\operatorname{Raz}^{13}$.

Além disso, e bem ao contrário do que costuma ser o caso na tradição positivista hartiana, Shapiro intenta agregar à sua teoria um forte apelo prático ${ }^{14}$, e não meramente analítico ou descritivo - sem embargo de estar declaradamente inserido na escola analítica do positivismo jurídico, cujo principal foco de estudo é a elucidação descritiva e moralmente desengajada da natureza e dos caracteres essenciais do direito e dos sistemas jurídicos ${ }^{15}$. Essa preocupação com a prática começa a descortinar, em minha opinião, a verdadeira relevância filosófica da produção do autor, pois claramente o separa de teóricos de peso dentro dessa mesma tradição de pensamento - como Raz, para quem o aspecto prático de uma teoria do direito é, senão totalmente desimportante, ao menos marginal ${ }^{16}$-, enquanto o aproxima, nesse traço específico, de pensadores não-positivistas - como Dworkin, autor da famosa observação de que a teoria do direito é o prólogo silencioso de toda decisão jurídica ${ }^{17}$.

O viés prático de Legality está essencialmente na percepção de que o modo pelo qual os juízes interpretam o direito (ou mediante o qual o identificam e determinam o seu

\footnotetext{
${ }^{13}$ COLEMAN, Jules. The architecture of jurisprudence. The Yale Law Journal, 121:2, 2012, pp. 2-80.

${ }^{14}$ Esse ponto é destacado por Brian Bix (2012, p. 447).

${ }^{15} \mathrm{O}$ primeiro capítulo de Legality é dedicado à exposição da particular visão que Shapiro tem acerca do que é a filosofia do direito, de quais são seus objetos e de qual é a sua metodologia. Recentemente, contudo, o autor mudou de posição a respeito desses temas, ao publicar artigo que alarga consideravelmente o escopo de sua visão teórica e propõe uma nova agenda para a disciplina. Não trato desse assunto neste trabalho, uma vez que meu foco investigativo permanece inalterado diante das novas posições do autor (cf. PLUNKETT, David, SHAPIRO, Scott. PLUNKETT, 2017).

${ }^{16}$ RAZ, Joseph. Two views of the nature of the theory of law: a partial comparison. Legal Theory, Volume 4, Issue 03, September 1998, pp. 249-282. Considero importante situar Shapiro em relação a Raz, ainda que sucintamente. Para tanto, baseio-me no esquema conceitual de Coleman (2012). Ambos, Raz e Shapiro, são positivistas exclusivistas e derivam o positivismo da análise que fazem dos elementos essenciais do direito ou dos elementos essenciais que compõem sua natureza. Para Raz, o traço mais importante dentre as verdades necessárias sobre a natureza do direito é a sua reivindicação de autoridade. Ele então apresenta um argumento conceitual (sobre a natureza do direito), aliado a um argumento normativo (sobre a autoridade), para disso concluir que apenas fatos sociais podem determinar a identidade e o conteúdo do direito. Shapiro, de seu turno, apresenta apenas argumentos conceituais (sobre a natureza do direito e sobre a natureza dos planos) para fundamentar sua teoria positivista. Ambos diferem, assim, quanto àquilo que consideram ser os caracteres essenciais que conformam a natureza do direito, bem como quanto ao tipo de defesa que fazem a respeito das conclusões que atingem a esse respeito: Raz avança argumentos normativos e conceituais em favor de sua forma de positivismo exclusivista, enquanto Shapiro constrói apenas argumentos conceituais em prol da sua. Por esse prisma, ao menos em uma primeira mirada, Shapiro parece ser um positivista mais hardcore do que Raz - embora eu entenda, como se verá ao longo deste trabalho, que sua radicalidade positivista é apenas aparente.

${ }^{17}$ DWORKIN, Ronald. Law's empire. Cambridge/London: The Belknap Press of Harvard University Press, 1986, p. 90.
} 
conteúdo), e portanto como decidem no direito, é dependente do conceito de direito que eles aceitam. Para Shapiro não é possível determinar qual seria o método correto de interpretação do direito sem que antes se ofereça resposta à pergunta filosófica "o que é o direito?". A resposta que ele mesmo apresenta quanto a esse questionamento irá, no entender dele, fixar o método pelo qual será possível estabelecer a adequada metodologia interpretativa para a solução de um problema jurídico. Noutras palavras, Shapiro extrairá de seu conceito de direito uma metateoria da interpretação jurídica que possibilitará ao juiz encontrar a maneira acertada de interpretar o direito e de decidir sobre questões jurídicas, sejam elas controvertidas ou não. Pode-se até mesmo afirmar que o autor é um dos únicos teóricos positivistas que se ocupa de articular com profundidade uma teoria da decisão jurídica.

Shapiro também rompe laços com alguns positivistas ao aceitar como cruciais e carentes de uma resposta definitiva algumas das críticas de Dworkin ao positivismo jurídico, particularmente aquelas que atingem a tese da separação entre direito e moral, bem como a formulação hartiana de regra de reconhecimento. Grosso modo, essas objeções afirmam que (1) a gramática lógica envolvida na decisão judicial necessariamente aponta para a inviabilidade de se considerar o direito e a moral como domínios normativos estanques, bem assim que (2) a utilização, pelos juízes, de standards jurídicos que são válidos em função de seu conteúdo valorativo, e não de seu pedigree, e que portanto dependem de justificação para além do direito positivado, aliada (3) ao surgimento de desacordos teóricos em torno dessa justificação (e do conceito de direito que a viabiliza), esvaziam a noção de que poderia haver uma regra de reconhecimento que fosse determinante do conteúdo do direito em um dado sistema e definidora das obrigações jurídicas nele encontráveis ${ }^{18}$.

É importante desde logo apontar o que quero dizer quando falo em tese da separação. Tradicionalmente ela é compreendida como o enunciado de que a validade de uma norma jurídica não depende de sua correção moral, mas apenas de seu pedigree ou de sua fonte social. Tanto Hart quanto Dworkin fazem expressa referência a essa concepção,

\footnotetext{
${ }^{18}$ A crítica aparece primeiramente em no célebre The modelo f rules I (In:DWORKIN, Ronald. Taking rights seriously. Cambridge: Harvard University Press, 1977, pp. 14-45), mas recebe sua articulação mais extensa em Law's empire. Dworkin retorna a esse tema em diversos escritos posteriores (DWORKIN, Ronald. Justice in robes. Cambridge/London: The Belknap Press of Harvard University Press, 2006; DWORKIN, Ronald. Justice for hedgehogs. Cambridge/London: The Belknap Press of Harvard University Press, 2011), mas seus componentes essenciais permanecem os mesmos.
} 
caracterizando-a como traço central do positivismo jurídico. Ela diz respeito ao tipo de relações que seriam (in)existentes entre o direito e a moral no estrito campo da validade jurídica. Os positivistas não afirmam que direito e moral são absolutamente incomunicáveis e distintos um do outro. Como defender a concepção de mínimo moral de Hart, por exemplo, nesses termos radicais? Como compreender o conceito de autoridade em Raz senão como um tema de moralidade política ${ }^{19}$ ? Mesmo assim eles entendem, em regra, que a ideia de separação tem especial relevância na discussão da classificação de um certo standard normativo como jurídico, e que em sua discussão pode ser encontrada a própria definição daquilo que seria o positivismo jurídico ${ }^{20}$.

Shapiro, de certo modo, investe contra essa tradição minimalista da ideia de separação ao dizer que a identificação do direito e a determinação de seu conteúdo não dependem de deliberação moral. Ele na verdade está avançando duas afirmações distintas sob a roupagem da tese da separação, (1) a primeira relativa à existência do direito e das instituições jurídicas, (2) a segunda referente à interpretação das normas jurídicas. Direito e moral estão separados no que se liga à existência do direito e das instituições tipicamente jurídicas porque estes estão fundados unicamente em fatos sociais. Direito e moral estão separados no que tange à interpretação jurídica porque, dada a natureza do direito, este não pode cumprir sua função se permitir ou tolerar o recurso à deliberação moral nas decisões jurídicas - do que decorre que a razão jurídica deve ser amoral. Parece evidente que a separação entre direito e moral na esfera da validade das normas jurídicas está contida nessa posição do autor. No entanto ela não a esgota. Desse quadro é possível concluir, ademais, que o positivismo de Shapiro é definido pela observação de que fatos jurídicos são determinados exclusivamente por fatos sociais ${ }^{21}$. Fatos jurídicos são fatos sobre a existência ou sobre o conteúdo de sistemas jurídicos, e portanto se referem às duas afirmações que Shapiro propõe quanto à noção de separação entre direito e moral. A moral não pode ter participação na determinação de tais fatos, mas isso não preclui a possibilidade de que direito e moral ainda assim mantenham algum tipo de ligação entre si.

\footnotetext{
${ }^{19} \mathrm{E}$ também como reconhecimento de que ao menos parte da visão jusnaturalistas sobre o direito está correta, conforme aponta Carla Henriete Bevilacqua Piccolo (PICCOLO, Carla Henriete Bevilacqua. A moral e o conceito de direito em H. L.A. Hart. 2011. 129 f. Dissertação (Mestrado em Direito) - Faculdade de Direito, Universidade de São Paulo, São Paulo, 2011).

${ }^{20}$ A tese da separação, nesse contexto, serviria para definir o positivismo jurídico como uma teoria do direito que nega a possibilidade de que a juridicidade de uma norma possa depender de sua correção moral, bem como para diferenciá-lo do direito natural, que preconizaria o contrário.

${ }^{21}$ PLUNKETT, David. Legal positivism and the moral aim thesis. Oxford Journal of Legal Studies. Vol. 33 (3), Autumn 2013a, pp. 563-605, p. 585.
} 
O rompimento de Shapiro com esse traço da herança positivista é especialmente importante porque, paralelamente à implementação da noção de separação entre direito e moral nos aspectos acima mencionados, ele reconhece que ambos estão conectados de alguma maneira relevante ao afirmar que o direito tem um propósito moral constitutivo de sua própria natureza ${ }^{22}$. Não está claro se ele concorda com a análise de Coleman no sentido de que ele, Shapiro, se aproximaria de Raz ao entender que o direito e a moral não apenas estão intimamente ligados um ao outro, como também que o direito está a serviço da moral. A aparente radicalidade da posição de Coleman nesse particular talvez levante preocupações quanto ao acerto de sua observação, mas esta não deixa de ser relevante por conta disso $^{23}$. Se ele estiver certo, então ou bem (1) Shapiro não é um positivista nos termos em que ele mesmo se define, ou bem (2) o positivismo jurídico, antes de prestigiála, nega a tese da separação. Principalmente no primeiro desses casos a afirmação de que o direito teria um propósito moral poderia sugerir a presença de uma contradição no âmago da teoria de Shapiro, máxime se essa formulação for compreendida como normativa ${ }^{24}$. De todo modo, quando me referir à tese da separação estarei me reportando à sua específica vertente shapiriana. Entendo que isso permitirá o exame do positivismo de Shapiro em seus próprios termos.

Tendo em conta que a tese da separação, conforme pode ser compreendida na obra de Shapiro, necessariamente demanda que o direito tenha fontes exclusivamente sociais, considero que a assim chamada tese das fontes, para os fins deste trabalho, está contida na tese da separação. Não é minha preocupação, contudo, discutir se essa relação de continência seria ou não existente de fato. Nada de relevante para este estudo decorre dessa possível discussão, mesmo porque ambas essas posições teóricas caminham juntas e são indissociáveis uma da outra na obra de Shapiro - se a tese da separação for verdadeira na acepção aqui tratada, então a tese das fontes necessariamente também o será. Por esse

\footnotetext{
22 2011, pp. 213-215; 391.

${ }^{23}$ COLEMAN, 2012. Mesmo que Coleman esteja correto, entendo que a tese da separação ainda se configura, quando menos, em um dispositivo teórico relevante para a compreensão da racionalidade empregada na descrição positivista do direito. Mesmo que não seja mais razoável falar em separação entre direito e moral no nível metateórico, no âmbito das explicações positivistas para problemas como os da normatividade do direito e da racionalidade da decisão judicial a ideia de separação ainda é crucial. A própria obra de Shapiro é um bom exemplo disso. Assim, examino o compromisso do autor com a tese da separação não por entender que ela faz ou deixa de fazer sentido, mas por considerá-la como uma lente particularmente poderosa pela qual uma teoria do direito (ainda) pode ser examinada. $\mathrm{O}$ fato de ela própria eventualmente se configurar em fruto de uma opção moral anterior do teórico, ou em exigência do serviço que o direito presta à moral (como diz Coleman), não altera esse quadro.

${ }^{24}$ Oportunamente tratarei desse ponto com mais detalhes.
} 
motivo sempre que me reportar à tese da separação estarei também me referindo à ideia de que o direito tem fontes exclusivamente sociais ${ }^{25}$.

Podemos identificar duas dimensões, ou dois contextos, em que as críticas dirigidas à tese da separação ${ }^{26}$ e à regra de reconhecimento podem ser situadas e discutidas em relação à obra de Shapiro.

A primeira delas é a da fundação ou das bases do direito. O direito é constituído convencionalmente? A regra de reconhecimento (ou o plano-mestre, para usar o glossário de Shapiro) é uma convenção cujos méritos morais são indiferentes para sua identificação e interpretação? É parte da identidade do direito o seu caráter convencional? De que maneira uma convenção pode criar obrigações jurídicas, principalmente para os oficiais de um sistema jurídico? Essa convenção pode ou não conter elementos morais? Ela é capaz de oferecer aos oficiais do sistema jurídico razões para colocá-la em prática? De quais espécies são - ou devem ser - essas razões? Tais perguntas foram formuladas e (não) respondidas ao longo dos anos por diversos autores, dentre eles o próprio Hart, cada um deles enfatizando pontos diferentes das críticas dirigidas ao positivismo jurídico. Alguns, como Julie Dickson ${ }^{27}$ e Leslie Green ${ }^{28}$, negaram peremptoriamente o caráter convencional

\footnotetext{
${ }^{25}$ Noel Struchiner, embora utilizando nomenclatura diferente, destaca que existe um mínimo denominador comum entre todos os teóricos positivistas: a tese do positivismo conceitual, segundo a qual a existência e o conteúdo do direito independem do preenchimento de qualquer critério moral, resumindo-se a questões resolúveis pela identificação correta de suas fontes. São decorrências dessa tese fundamental as ideias de que (1) há uma separação conceitual entre direito e moral e de que (2) há sempre um componente de indeterminação a caracterizar o direito. Ele avança a afirmação de que essa posição positivista básica é normativamente inerte, o que implica o reconhecimento de que ela não tem consequências práticas e de que pode ser acoplada a diversos modelos decisórios (ou a variadas maneiras de se lidar com as normas jurídicas). Mais adiante mostrarei como o pensamento de Shapiro parece não se adequar a esse esquema conceitual ao propor um desenho determinado de decisão (aquele ligado à lógica dos planos) que seria imposto aos agentes decisórios pela natureza do direito (cf. STRUCHINER, Noel. Para falar de regras. 2005. 191 f. Tese (Doutorado em Filosofia) - Departamento de Filosofia, Pontifícia Universidade Católica do Rio de Janeiro, Rio de Janeiro, 2005).

${ }^{26}$ Interessantemente Shapiro não discute a tese da separação como um elemento notavelmente importante de sua teoria do direito. Na realidade ele só trata expressamente dela em uma nota de pouco mais de meia página. Talvez isso aconteça porque ele reconhece que o direito e a moral estão, de alguma forma, ligados conquanto não essencialmente ou necessariamente ligados. Mesmo assim a tese permeia toda a sua construção teórica, visto que o autor insiste em afirmar - e nisto está o seu comprometimento com o positivismo exclusivista - que a identificação e a determinação do conteúdo do direito se dão por recurso a fatos exclusivamente sociais. A teoria shapiriana está inegavelmente atrelada, então, à tese da separação, ainda que apenas sob o prisma da explicação de sua racionalidade.

${ }^{27}$ DICKSON, Julie. Is the rule of recognition really a conventional rule? Oxford Journal of Legal Studies, Vol. 27, No.3, 2007, pp. 373-402.

${ }^{28}$ GREEN, Leslie. Positivism and conventionalism. Canadian Journal of Law and Jurisprudence, Vol. XII, No. 1, January 1999, pp. 35-52.
} 
da regra de reconhecimento hartiana. Outros, como Jules Coleman ${ }^{29}$, embora convencionalistas, sustentaram que a regra de reconhecimento pode contingentemente encampar fatos morais ${ }^{30}$. Outros ainda, como é o caso de Andrei Marmor, buscaram refinar o conceito de convenção para dar conta dos argumentos levantados pelos críticos do convencionalismo $^{31}$. Shapiro dirá que as respostas apresentadas pelos positivistas para as perguntas aqui exemplificativamente mencionadas, particularmente por Hart, são inadequadas, em seguida avançando novas soluções para essas perenes questões.

Adiante tratarei de pontos mais específicos dessa discussão, que serão parte do foco deste trabalho. Desde já, contudo, afirmo que sigo Gerald Postema ${ }^{32}$ e Ronaldo Porto Macedo Junior ${ }^{33}$ quanto a compreender (1) uma convenção social como uma norma social praticada cujo funcionamento como norma depende, em alguma medida, de ela ser efetivamente praticada, bem como (2) o convencionalismo jurídico como a tese de que a natureza e a normatividade do direito tomam por base uma prática social de tipo convencional $^{34}$. Destaco que essa definição do que seja o convencionalismo jurídico é propositalmente larga, não apenas por serem várias as possíveis formas de compreensão do assunto (e da própria ideia de convenção), como também porque ela dá margem a que seja destacado unicamente o que é fundamental dentre o conjunto de teorias convencionalistas do direito: a ideia de que, na base do direito, está uma prática social convencional ${ }^{35}$.

\footnotetext{
${ }^{29}$ Embora Coleman e Shapiro partilhem o apreço pelo positivismo e pelo convencionalismo, é interessante notar que a questão em torno de se saber se a regra de reconhecimento pode ou não conter critérios morais para determinação da juridicidade de uma regra coloca ambos em trincheiras opostas do debate entre inclusivistas e exclusivistas. Coleman defende uma concepção de positivismo jurídico de feição inclusivista, enquanto Shapiro, como já dito, permanece no campo exclusivista.

${ }^{30}$ COLEMAN, 2001. Essa admissão marca a mais fundamental diferença entre o positivismo inclusivo, ou inclusivista, ao qual Coleman está filiado, e o exclusivista.

${ }^{31}$ MARMOR, Andrei. Interpretation and legal theory. Oxford/Portland: Hart Publishing, 2005. Para uma detalhada comparação entre as teorias de Shapiro e Marmor, ver GARCIA, Edgar Ramón Aguilera. La naturaleza del derecho: Están nuestras prácticas jurídicas fundadas en una convención constitutiva o en un plan compartido? Alegatos, Núm. 81, mayo/agosto 2012, pp. 347-372.

32 POSTEMA, Gerald. Coordination and convention at the foundations of law. The Journal of Legal Studies. Vol. 11, No. 1, January 1982, pp. 165-203.

${ }^{33}$ MACEDO JUNIOR, 2013a, p. 9.

${ }^{34}$ MACEDO JUNIOR, 2013a, p. 10.

35 A moderna concepção de convenção aparece na obra da David Lewis (LEWIS, David. Convention. A philosophical study. Oxford: Blackwell Publishers, 2002). Dworkin, por outro lado, enxerga o convencionalismo como uma espécie de versão interpretativa do positivismo: uma teoria do direito fundada em determinados valores políticos que justificam uma interpretação de nossas práticas jurídicas centrais segundo a qual o direito funcionaria do modo como os positivistas dizem que ele funciona (DWORKIN, 1986, pp. 114-150). Os positivistas em geral rejeitam essa visão, pois entendem o positivismo jurídico como uma teoria descritiva, e não interpretativa, do direito. O próprio Shapiro pensa dessa forma. Para os fins colocados nesta dissertação, penso que não é necessário ingressar nesse ponto específico do debate entre
} 
A segunda dimensão do debate se localiza no plano da prática jurídica, ou, poderíamos dizer, da fenomenologia do julgar. Shapiro leva a sério a crítica dworkiniana segundo a qual a descrição positivista do direito não dá conta de explicar os nossos desacordos teóricos, tampouco o dever de obediência ao direito que os juízes reconhecem ter ao desempenhar suas funções institucionais. Ele afirmará que autores como Brian Leiter estão errados ao dizer que os desacordos teóricos deveriam ser tomados como fenômenos de pouca ou nenhuma importância para a filosofia do direito, os quais sequer demandariam explicação específica ${ }^{36}$. Entretanto dirá, contra Dworkin, que a existência de desacordos teóricos em nossas práticas jurídicas é inteligível mesmo no interior de uma concepção positivista do direito - isto é, de uma teoria que defina os fundamentos dos fatos jurídicos como sendo fatos exclusivamente sociais. Ele concluirá que o argumento dworkiniano não se presta a demonstrar que a identificação e a determinação do conteúdo do direito dependem mesmo de fatos morais (compreendidos como razões ou justificações valorativas que permitam que algo venha a ser descrito como direito), e que a teoria do direito de Dworkin está errada porque derrota a função do direito, que está inscrita em sua natureza e que, para Shapiro, é a de sanar controvérsias morais.

Discutir a obra de Shapiro, então, é importante por diversos motivos. Do ponto de vista teórico, os principais deles podem ser sumarizados nas afirmações de que (1) seu posicionamento no campo positivista revela com singular clareza os rasgos existentes no tecido dessa tradição de pensamento, bem como de que (2) sua construção teórica procura enfrentar e responder as objeções mais contundentes que podem ser dirigidas ao positivismo jurídico por seus críticos externos, reconhecendo-as como fortes e pertinentes.

Os adversários teóricos de Shapiro estão tanto dentro quanto fora da tradição à qual ele está filiado, e, ainda que ele esteja equivocado em algumas de suas posições - ponto que explorarei com mais profundidade ao longo deste trabalho -, é fundamental compreendê-las e apontar onde estão os seus equívocos. A importância teórica dessa elucidação, e portanto a relevância teórica deste trabalho, está no fato de que os desacertos de Shapiro e a forma pela qual é possível detectá-los são paradigmáticos no que se refere

Dworkin e os adeptos do positivismo, e por isso trabalho com uma concepção propositalmente ampla, do ponto de vista descritivo, do que seja o convencionalismo.

${ }^{36}$ LEITER, Brian. Explaining theoretical disagreement. The University of Chicago Law Review. Vol. 76, 2009, pp. 1215-1250; LEITER, Brian. Theoretical disagreements in law: another look. Disponível em <https://ssrn.com/abstract=2830732>. Acesso em 15/09/2016. 
ao tipo de debate que caracteriza a filosofia do direito contemporânea, marcado por um forte caráter metodológico e, cada vez mais, metateórico.

Isso no entanto não significa que o estudo da obra de Shapiro somente produza frutos teóricos. Seu trabalho também gera consequências práticas notáveis. Ele mesmo destaca um exemplo simples, porém revelador, do tipo de impacto que sua visão acerca do que é o direito exerce sobre a prática jurídica: o do casamento entre pessoas de mesmo sexo. Afirmando que é possível defendermos as mais variadas convicções sobre o significado desse conceito o autor assevera que a lógica dos planos nos leva à conclusão de que o casamento em termos jurídicos será apenas aquele celebrado entre homem e mulher sempre que o direito positivo disser que esse é o caso ${ }^{37}$. Por esse prisma a decisão que nosso Supremo Tribunal Federal (STF) tomou no julgamento conjunto da ação direta de inconstitucionalidade (ADI) de $\mathrm{n}^{\mathbf{o}} 4277^{38}$ e da arguição de descumprimento de preceito fundamental (ADPF) de $\mathrm{n}^{\mathrm{o}} 132^{39}$ seria contrária ao direito brasileiro de então - e o mesmo teria de ser dito, exemplificativamente, quanto àquilo que a corte decidiu na ADPF de $\mathrm{n}^{\circ}$ $54^{40}$, que permitiu o aborto dos chamados fetos anencefálicos à míngua de expressa previsão legal nesse sentido.

Essa espécie de posição pode ser vista como paradigma de um formalismo possivelmente retrógrado que fortaleceria o status quo e impediria a compreensão do direito em termos de algum ideal substantivo de justiça que pudesse ser defendido mais abertamente pelos juízes. Contudo, pode também ser abraçada por juristas refratários ao que se convencionou chamar de pamprincipiologismo - isto é, o uso de princípios genéricos e sem peso normativo como fundamento de decisões judiciais que refletem nada mais do que as idiossincrasias dos juízes que as prolatam ${ }^{41}$. Para pensadores dessa matriz uma teoria como a de Shapiro seria hábil para ao mesmo tempo (1) fundamentar uma

\footnotetext{
37 2011, p. 227.

38 BRASIL. Supremo Tribunal Federal. Ação Direta de Inconstitucionalidade no 4277, Brasília, DF, 5 de maio de $2011 . \quad$ Disponível em <http://www.stf.jus.br/portal/geral/verPdfPaginado.asp?id=400547\&tipo=TP\&descricao=ADI\%2F4277>. Acesso em 20/12/2017.

39 BRASIL. Supremo Tribunal Federal. Arguição de Descumprimento de Preceito Fundamental $\mathrm{n}^{\circ} 132$, Brasília, DF, 5 de $\quad$ maio de $2011 . \quad$ Disponível <http://redir.stf.jus.br/paginadorpub/paginador.jsp?docTP=AC\&docID=628633>. Acesso em 20/12/2017. 40 BRASIL. Supremo Tribunal Federal. Arguição de Descumprimento de Preceito Fundamental $n^{\circ} 54$, Brasília, DF, $12 \quad$ de abril $\quad$ de $2012 . \quad$ Disponível $\quad$ em $<$ http://redir.stf.jus.br/paginadorpub/paginador.jsp?docTP=TP\&docID=3707334>. Acesso em 20/12/2017.

${ }^{41}$ Cf. STRECK, Lênio Luiz. Do pamprincipiologismo à concepção hipossuficiente de princípio. Dilemas da crise do direito. Revista de Informação Legislativa, Brasília, a. 49, n. 194, abr/jun 2012, pp. 7-21.
} 
oposição teoricamente robusta ao posicionamento dos magistrados adeptos desse expediente e (2) evitar as censuras tradicionalmente direcionadas ao positivismo kelseniano. Isso porque, embora positivista, Shapiro constrói uma sofisticada teoria da decisão jurídica que prestigia o conteúdo do direito posto e que não se harmoniza com a afirmação de que o juiz no fundo simplesmente decide como quer. Como representante de um positivismo que valoriza a distinção entre regras primárias e secundárias, ademais, o pensamento shapiriano também protegeria os nossos sistemas jurídicos das consequências advindas do esvaziamento da ideia de regra de reconhecimento - notadamente da incerteza, da ineficiência e da estagnação ${ }^{42}$.

Recentemente um juiz federal de São Paulo se mostrou filiado a essa última corrente ao proferir sentença no processo de $n^{\circ} 0008950-50.2016 .403 .6100^{43}$. Em suma, aquele magistrado fez uso do arsenal teórico de Shapiro para tomar posição sobre qual é o seu papel institucional em um sistema jurídico democrático (aplicar os planos estabelecidos pelo parlamento, ao invés de tomar o lugar do legislador e reformá-los à luz de um ideal qualquer de justiça) e quais são os limites da interpretação jurídica em sede de decisão judicial (não podem extrapolar o sentido do texto legal a pretexto de dar concretude a princípios abertos que retratam um certo voluntarismo de quem decide).

Há então dividendos teóricos e práticos a extrair da obra de Shapiro, pelo que é realmente importante levá-lo a sério. Encaro sua obra não apenas com essa seriedade, mas, apesar de minha posição crítica em relação às teses do autor, também com um profundo respeito e uma forte admiração por sua produção filosófica, que despertou em mim interesse grande o suficiente para justificar a dedicação de alguns anos ao seu estudo.

Dito isso, na seção seguinte apresento esquematicamente o caminho que percorrerei nesta dissertação.

\footnotetext{
${ }^{42}$ Cf. adverte André Luiz Souza Coelho (COELHO, André Luiz Souza. Por que surgem as regras secundárias? Uma reinterpretação da fábula de Hart. Revista da Faculdade de Direito da UERJ - RFD, v. 1, n. 25, 2014a, p 18. Disponível em <http://www.e-publicacoes.uerj.br/index.php/rfduerj/article/view/11661>. Acesso em 10/10/2016).

${ }^{43}$ BRASIL. 2 ${ }^{\mathrm{a}}$ Vara Federal Cível da Subseção Judiciária da Capital do Estado de São Paulo. Ação no 0008950-50.2016.403.6100, São Paulo, SP, 20 de fevereiro de 2017. Disponível em <http://web.trf3.jus.br/diario/Consulta/BaixarPdf/15330>. Acesso em 20/12/2017.
} 


\section{O plano a ser seguido}

Como já afirmado, Shapiro é um positivista exclusivista e portanto está de alguma maneira comprometido com a tese da separação entre direito e moral. Esse comprometimento se verifica em dois níveis, especificamente (1) no da fundação do direito, ou daquilo que lhe serve de base, e (2) no da prática jurídica, ou da decisão judicial.

Para defender sua posição exclusivista Shapiro se vincula a uma certa concepção de racionalidade, que é a do planejamento. Ele segue Bratman ao dizer que os homens têm a inata capacidade de planejar e que o fazem porque necessitam atingir objetivos complexos contando com recursos racionais limitados. O planejamento permite ao homem manejar os meios adequados para chegar aos fins que ambiciona, sejam quais forem esses fins, e de forma independente de seus méritos valorativos ${ }^{44}$. Ele é uma ferramenta que se presta a cumprir as mais variadas funções, sejam elas boas ou más.

O fio condutor do trabalho é a relação entre dois pontos: (1) a implementação que se faz da tese da separação na obra de Shapiro e (2) a concepção de racionalidade instrumental que a possibilita. Meu argumento central é o de que o esforço de Shapiro falha nos dois níveis estudados, a despeito de sua grande sofisticação, porque essa racionalidade não é a do direito ${ }^{45}$.

No nível da fundação do direito Shapiro diz que a prática jurídica toma por base um plano compartilhado chamado de plano-mestre, em redor do qual se desenvolve um agir também compartilhado. Por dois motivos esse plano-mestre é normativo (ele tem autoridade) relativamente aos oficiais do sistema jurídico. Em primeiro lugar porque ele autoriza uma pessoa ou um grupo de pessoas a planejar pela comunidade, vindo tal autorização não de um outro plano ou de outra norma, mas da racionalidade instrumental que caracteriza a atividade de planejamento. Em segundo lugar porque os membros do grupo social normalmente seguem os planos criados pela autoridade, mesmo que não haja consenso em torno de seu conteúdo ou de seus méritos morais ${ }^{46}$.

\footnotetext{
44 2011, p., 118-153.

${ }^{45}$ Embora possa ter utilidade, como será melhor explicado adiante, em certos ramos específicos do direito.

46 2011, p. 180.
} 
Apresento nesse aspecto a ideia de que o plano-mestre shapiriano é uma reformulação da regra de reconhecimento de Hart. Para Shapiro essa reformulação é necessária porque a tese hartiana de que na base do direito se encontra uma prática social compartilhada, que por si só gera regras sociais, e que portanto produz normatividade, está errada. O erro hartiano é filosófico: como práticas e regras pertencem a categorias metafísicas distintas, práticas não podem gerar regras, ainda que sejam compreendidas como convenções coordenativas ${ }^{47}$. O plano-mestre de Shapiro, ao contrário disso, é capaz de dar origem a outros planos porque a sua normatividade é garantida não só pela prática social, mas fundamentalmente pelas normas da racionalidade instrumental característica do planejamento. Essas normas existem pelo simples fato de serem racionalmente válidas, e portanto não necessitam estar fundadas em alguma espécie de norma superior ${ }^{48}$, tampouco são constituídas apenas pela própria prática social. Elas são naturalmente normativas.

É importante observar que essa racionalidade não demanda dos oficiais do sistema que se engajem de modo prático no plano-mestre (prático no sentido de Hart, segundo o qual o fato de uma regra ser praticada se constitui em razão de ação para esses oficiais, que adotam quanto à regra de reconhecimento o ponto de vista interno - ou uma atitude crítica reflexiva que se assemelha à ideia de endorsement ${ }^{49}$ ), mas apenas que o aceitem de uma mirada instrumental. Isso significa, a rigor, o abandono do ponto de vista interno hartiano, que pressupunha uma certa intencionalidade compartilhada pelos oficiais. Na visão do autor ela também não envolve deliberação moral alguma, pelo que fica preservada e prestigiada a tese da separação nesse contexto. Segundo Shapiro, embora o direito use terminologia moral, o faz apenas do ponto de vista do próprio direito, que pode ser moralmente bom ou moralmente mau, de maneira que seu conteúdo é passível de ser descrito normativamente mesmo por quem não o aceite desde um ponto de vista interno ${ }^{50}$.

Tal posição alinha Shapiro ao convencionalismo ${ }^{51}$, uma vez que, para existir e funcionar como norma, o plano-mestre tem de ser praticado pelos oficiais do sistema. É um

\footnotetext{
47 2011, p. 103.

48 2011, p. 181.

${ }^{49}$ Cf. PATTERSON, Dennis. Explicating the internal point of view. SMU Law Review, No. 52, 1999, pp. 67-74.

${ }^{50} 2011$, pp. 111-113.

51 Talvez seja possível compreender a obra de Shapiro não como um exemplo de, mas antes como uma alternativa ao convencionalismo. Por esse raciocínio a noção de plano compartilhado substituiria a de convenção, ao invés de qualificá-la de alguma maneira. Tal parece ser a posição de Arthur Ripstein (2012, p. 201-202). Essa possibilidade, de início, parece plausível, porque o próprio autor se abstém de afirmar em
} 
convencionalismo peculiar, contudo, porque garante a normatividade do direito mediante apelo a um elemento específico e complementar à prática: as normas da racionalidade instrumental.

Sustento que a solução de Shapiro para a questão da autoridade do direito não é adequada sob o prisma de seu alistamento nas fileiras do positivismo jurídico, visto que não esclarece como o plano-mestre pode ser normativo para aqueles mesmos oficiais, fornecendo a eles razões para agir, se (1) a mera prática social, segundo o próprio Shapiro, não é capaz de fazê-lo, e se (2) o engajamento no plano-mestre, exigido deles, é apenas instrumental.

Aparentemente Shapiro somente muda de lugar o problema teórico que intentou resolver: sua proposta afasta a necessidade de se explicar quais razões os oficiais do sistema teriam para enxergar o plano-mestre como normativo (elas podem ser de qualquer natureza, uma vez aceito o plano), mas cria a necessidade de elucidação das razões que esses mesmos oficiais têm para aceitarem o plano e continuarem a aceitá-lo. Como essas razões são necessariamente morais, então o plano-mestre não pode ser identificado pelos oficiais, nem pode ter seu conteúdo conhecido por eles, sem que a moral participe dessas operações.

Meu argumento sobre isso tem duas partes principais. A primeira delas é construída a partir de uma observação de Dickson, enquanto a segunda está ligada a um insight de Verônica Rodriguez-Blanco.

Dickson afirma que o convencionalismo aparece tardiamente em Hart como uma tentativa de mostrar, em resposta a críticas de Dworkin, como a regra de reconhecimento pode dar razões aos oficiais para aceitá-la como obrigatória. Para a autora essa não foi a melhor estratégia. $\mathrm{O}$ que Hart deveria ter feito era ter retomado sua posição original, de $O$ conceito de direito, pela qual ficava claro que a regra de reconhecimento de fato não

Legality que sua teoria seria convencionalista, ou mesmo que o seu plano-mestre seria uma convenção. Contudo, em texto publicado no ano de 2002, Shapiro explicitamente fez afirmações nesse sentido, destacando que seu esforço teórico de bases bratmanianas se constituía em uma versão diferente de um mesmo tipo de estratégia disponível para os positivistas - a de explicar o direito pela via do convencionalismo. Possivelmente por não desejar carregar o ônus ligado a todas as críticas que já haviam sido lançadas contra essa mesma estratégia por seus mais diversos críticos, naquele texto ele conclui seu raciocínio dizendo que, mesmo assim, a ideia de convenção desempenharia um papel muito reduzido em sua construção teórica, bem como que devemos ser cautelosos ao rotular esta ou aquela teoria como convencionalista. 
fornecia aos oficiais razões jurídicas para considerá-la obrigatória, e, a partir dessa retomada, arquitetar uma nova explicação acerca de quais espécies de razões funcionam nessa consideração. Hart afirmava que as mais variadas razões podiam justificar a adesão dos oficiais à regra de reconhecimento, e insistia apenas em que elas não necessitavam ser morais. Caberia a Hart suplementar sua posição original, teorizando sobre essas razões, ao invés de se filiar ao convencionalismo. O convencionalismo, para Dickson, mantém abertas as questões de se determinar (1) como a regra de reconhecimento entrega razões de ação aos oficiais do sistema, (2) de que espécie são essas razões e (3) como, enfim, o direito pode ser normativo em relação a eles. Isso porque a solução convencionalista se limita a afirmar que o fato de haver uma prática jurídica de reconhecimento se constitui apenas em parte das razões que os oficiais têm para compreendê-la como obrigatória ${ }^{52}$.

Já Rodriguez-Blanco observa que o dilema da autoridade do direito só pode ser solucionado em conjunto com o seu correspondente dilema moral - isto é, o problema de se saber qual justificação moral existe para a autoridade do direito (que abordo especificamente do ponto de vista dos oficiais do sistema jurídico, e não da população em geral). Apresento essa segunda parte de meu argumento como complemento à crítica anterior, extraindo dela a conclusão de que as razões apontadas por Dickson como carentes de teorização são razões morais. Essa nova crítica pontua que a solução de Shapiro para o uso da linguagem moral na prática jurídica (ele se daria do ponto de vista do direito) não é correta porque reflete um olhar teórico, e não prático (ou deliberativo) sobre aquilo que o direito é ou exige. O ponto de vista deliberativo, segundo Rodriguez-Blanco, carece de justificação moral porque deve estar referido a um bem (ou valor). Logo, pode-se dizer que as razões que Dickson entende como carentes de teorização são (boas) razões morais, e que o plano-mestre de Shapiro só pode funcionar como tal se os oficiais do sistema o aceitarem por conta de uma (boa) razão moral ${ }^{53}$.

Observo que a crítica oriunda da junção dessas duas linhas argumentativas não pode ser rebatida com base nas normas da racionalidade instrumental do planejamento. A uma porque o funcionamento dessa racionalidade envolve, em alguma medida, deliberação

\footnotetext{
52 DICKSON, Julie. Is the rule of recognition really a conventional rule? Oxford Journal of Legal Studies, Vol. 27, No.3, 2007, pp. 373-402. A autora, no limite, está ao lado de Raz ao fundar a obrigação jurídica em elementos externos ao direito. Shapiro, de seu turno, tenta trazer o fundamento da obrigação jurídica de volta ao interior do próprio direito, para tanto afirmando que a racionalidade dos planos é a racionalidade jurídica por excelência porque isso é o que se extrai da correta identificação da natureza do direito.

53 2011, pp. 86-106.
} 
moral, seja porque o agente (1) se vincula a um plano em função de uma avaliação positiva que faz de sua própria autodeterminação e de sua própria autonomia, seja porque (2) valora também positivamente as justificações profundas desse mesmo plano ${ }^{54}$. A duas porque o problema consistente em verificar se a nossa racionalidade instrumental seria ou não capaz de nos fornecer razões para ação subsistiria ainda que a primeira objeção pudesse ser vencida - e porque a pergunta concernente a essa capacidade deve ser respondida de modo negativo, de acordo com John Broome ${ }^{55}$ e R. Jay Wallace ${ }^{56}$.

Após discutir um argumento convergente de Bratman, no sentido de que a teoria de Shapiro não vence o desafio concernente a explicar por que os oficiais do sistema jurídica aceitam o plano-mestre e continuam a praticá-lo, concluo que, do ponto de vista da fundação do direito, a tese da separação não pode ser defendida pela racionalidade do planejamento: mesmo que aceitemos a ideia de que somos agentes planejadores sujeitos a uma determinada racionalidade instrumental, a lacuna entre (1) a existência de um planomestre e (2) a sua capacidade de cometer razões de ação aos oficiais que são seus destinatários, que Shapiro enxergou e tentou superar permanecendo positivista, só pode ser preenchida por deliberação moral, incompatível com o projeto do positivismo jurídico exclusivista.

Já no nível da prática jurídica a tese da separação aparece em Shapiro como uma imposição da lógica dos planos (e portanto da racionalidade do planejamento). Segundo essa lógica, para identificar o direito e determinar seu conteúdo o juiz não pode deliberar moralmente, porque se o fizer impedirá o direito de cumprir sua função ${ }^{57}$.

Para que isso faça sentido Shapiro necessita vencer o argumento dos desacordos teóricos proposto por Dworkin. Esses desacordos se referem às condições de verdade das afirmações que formulamos sobre o conteúdo do direito. O argumento dworkiniano pretende demonstrar, dentre outras coisas, que a prática jurídica só pode ser compreendida interpretativamente $^{58}$, e que os tais desacordos não são explicáveis a partir de uma

\footnotetext{
${ }^{54}$ BRATMAN, Michael. Taking plans seriously. In: MILLGRAM, Elijah. Varieties of practical reasoning. London/Cambridge: The MIT Press, 2001, pp. 203-220.

${ }^{55}$ BROOME, John. Does rationality give us reasons? Philosophical Issues, 12, Normativity, 2005, pp.321337.

${ }^{56}$ WALLACE, R. Jay. Normativity, commitment, and instrumental reason. Philosopher's Imprint, Volume 1, No. 3, December 2001, pp. 1-26.

${ }^{57} 2011$, p. 310.

${ }^{58}$ A expressão literal seria "interpretivamente". Fiz uso da forma constante do texto apenas por razões estilísticas.
} 
racionalidade meramente instrumental, mas de uma racionalidade referida a valores cujo significado não advém de acordo convencional. Isso porque os juízes continuam buscando justificações jurídicas para as suas decisões mesmo quando o direito positivo parece exaurido - o que significa, sobretudo, que o conjunto das justificações jurídicas não se esgota no direito socialmente posto e não é identificável por deliberação puramente sociológica $^{59}$. Para que a conduta dos juízes seja juridicamente inteligível é necessário dar conta dessa busca por justificações jurídicas não positivadas e não fundadas apenas em fatos sociais ou em acordos convencionais.

Shapiro tenta rebater Dworkin dizendo que os desacordos teóricos incidem sobre metodologias interpretativas, cuja adequada determinação pode ser feita sem apelo à moral. Há três fatos envolvidos nessa determinação, nomeadamente (1) os propósitos dos criadores do sistema jurídico, (2) a economia da confiança que esses mesmos criadores estabeleceram ao criá-lo, e (3) a interação entre esses dois pontos. Os desacordos se refeririam a esses três fatos, bem como à leitura que os oficiais fazem a respeito da espécie de sistema jurídico do qual eles participam. Há desacordos porque os juízes podem divergir sobre os dois primeiros, sobre o modo pelo qual tais elementos interagem entre si e sobre como esse procedimento deve funcionar à luz do tipo de sistema em questão. Isso prestigiaria a tese da separação no nível da prática jurídica porque a resolução dessas divergências dependeria apenas da investigação sociológica desses temas, e não de deliberação moral ${ }^{60}$.

A tentativa não funciona, em minha visão, porque parte de uma má descrição da atividade dos juízes. Ela não explica o motivo pelo qual os julgadores empregam deliberação moral para identificar o conteúdo do direito, decidindo a partir daquilo que enxergam como razões jurídicas - e por qual causa o fazem mesmo quando estão diante de casos fáceis, e ainda quando não há dúvida sobre qual seria o método correto para interpretar o direito. Dito de outro modo, ela não dá conta de esclarecer por qual motivo os juízes compreendem sua mais relevante obrigação jurídica, notadamente a de decidir conforme o direito, a partir de um ponto de vista moral não convencional. Se a racionalidade da decisão judicial é a da deliberação moral, então a lógica dos planos não é a lógica da decisão judicial, e a tese da separação não subsiste nesse campo.

\footnotetext{
${ }^{59}$ DWORKIN, 1986, pp. 1-44.; MACEDO JUNIOR, 2013a , pp. 8.

${ }^{60}$ SHAPIRO, Scott. Summary. Book Symposium. Legality, by Scott J. Shapiro. Analysis Reviews. Vol. 72, No. 3, July 2012, pp. 537-541.
} 
Minhas conclusões finais são as de que (1) a racionalidade do planejamento não é a racionalidade do direito, (2) a razão jurídica não é meramente instrumental, mas é prática no sentido de demandar do agente que assuma uma postura deliberativa e valorativa quanto àquilo que o direito exige, e, finalmente, de que (3) a implementação que Shapiro faz da tese da separação é insustentável nos dois níveis em que eu a discuto.

Tais posições serão desenvolvidas ao longo dos próximos quatro capítulos deste trabalho. No de $n^{\circ}$ II exporei em linhas gerais a teoria do direito de Shapiro, dando especial ênfase aos seus alicerces bratmanianos e apresentando os contornos de um exemplo paradigmático largamente utilizado pelo autor em Legality, que é o do planejamento de um jantar. Meus objetivos principais serão os de mostrar que (1) todo o poder explicativo da teoria do direito de Shapiro depende de aceitarmos que a nossa racionalidade é a racionalidade do homem planejador, bem como que (2) ela está sensivelmente comprometida com a tese da separação.

O capítulo seguinte servirá para debater as falhas que Shapiro atribui à teoria de Hart e a expor as soluções shapirianas para essas falhas. Essa discussão revelará que (1) as respostas de Shapiro para os problemas do positivismo hartiano são inteiramente dependentes da racionalidade descrita no capítulo anterior, bem assim que (2) elas de algum modo prestigiam a tese da separação. Prosseguirei com a exploração da ideia de que Shapiro reconstrói o conceito de regra de reconhecimento na tentativa de resolver a circularidade presente na resposta hartiana ao que ele chama de Dilema da Possibilidade, e que ele apresenta uma nova explicação convencionalista para a normatividade do direito relativamente aos oficiais do sistema jurídico. Discutirei os contornos desse convencionalismo e a inevitabilidade de que ele seja adotado quando são aceitas as bases da teoria do autor, enquanto debato a posição teórica que ela ocupa relativamente às obras de David Lewis e de David Hume.

A partir da identificação das duas dimensões em que a teoria da separação pode ser situada, no quarto capítulo colocarei em confronto a posição de Shapiro com a crítica de que a regra de reconhecimento não deve ser entendida convencionalmente. A oposição a Shapiro, neste ponto, virá de argumentos tecidos por Dickson e Veronica RodriguezBlanco. Procurarei esclarecer, com apoio nos escritos dessas autoras, bem como em observações de Bruno Celano e de Damiano Canale, como o convencionalismo de Shapiro 
não explica a normatividade do direito ao não dar conta do fornecimento de razões para agir, pelo plano-mestre, aos oficiais do sistema jurídico. Também abordarei argumentos de Broome e de Wallace quanto à impossibilidade de que a razão instrumental, usada por Shapiro como solução para esse problema, nos forneça razões para ação. Ao final, discutirei como o próprio Bratman desautoriza as conclusões de Shapiro no que se refere ao potencial que a teoria dos planos apresenta para explicar a normatividade do direito, bem como retomarei o exemplo do jantar shapiriano à luz dessas críticas, expondo assim os limites da posição do autor.

No quinto capítulo deste trabalho esclarecerei que a teoria de Shapiro também não resiste à crítica vinda da prática jurídica. Discorrerei sobre um dos vários aspectos do argumento dworkiniano dos desacordos teóricos, particularmente o de que a racionalidade da decisão judicial está necessariamente referida a valores não fixados em convenções sociais, examinarei a resposta de Shapiro a esse argumento e concluirei que sua posição também não explica o que fazemos quando decidimos no direito. A correta descrição de nossa prática, enfim, esvazia a tese da separação e não se mostra compatível com a racionalidade do planejamento. Novamente revisitarei o jantar de Shapiro para mostrar como a crítica tem efeitos mesmo sobre uma atividade aparentemente simples e em tese imune a esse tipo de controvérsia.

Ao final apresento conclusão no sentido de que, a despeito de estar equivocada em seus elementos essenciais, a obra de Shapiro presta à teoria do direito o grande serviço de mostrar que (1) insistir na tese da separação no âmbito da identificação do direito e da determinação de seu conteúdo, bem como (2) reduzir a razão jurídica a uma razão instrumental ou técnica são caminhos teóricos que devem ser abandonados em definitivo, porque incompatíveis com o tipo de objeto de estudo em que o direito consiste. Acrescento a isso algumas considerações sobre aspectos da teoria do autor que se afiguram interessantes para o avanço da teoria do direito, dentre os quais se destacam (1) a ideia de uma economia da confiança presente nos sistemas jurídicos, bem como (2) a própria noção de plano jurídico, que pode ter aplicação relevante em alguns ramos ou contextos específicos do direito, mas que depende, para tanto, de adequada justificação moral. 


\section{CONCLUSÃO}

I am very cautious of people who are absolutely right, especially when they are vehemently so. ${ }^{245}$

Neste trabalho pretendi demonstrar que a implementação da tese da separação na obra de Scott Shapiro, viabilizada pela incorporação da racionalidade do planejamento aos debates da filosofia do direito, é indefensável em dois níveis de análise, notadamente o da fundação do direito e o da prática jurídica.

Após apresentar minhas considerações introdutórias por meio do capítulo I, no seguinte intentei demonstrar que a ideia central da TPD é a de que a atividade jurídica é uma atividade de planejamento social em que as instituições jurídicas planejam para as comunidades sobre as quais reivindicam autoridade. Procurei dar sentido a essa colocação apresentando os traços essenciais da teoria shapiriana dos planos, para depois expor os elementos principais da teoria do direito do autor.

Dividi tal capítulo em duas seções. Na primeira discuti como a teoria dos planos de Shapiro é uma implementação do pensamento de Bratman. Os pontos mais relevantes da tese bratmaniana, no que se refere a este trabalho, estão ligados à caracterização do homem e da racionalidade humana presentes na obra do autor, e que pode ser sumarizada nas afirmações de que (1) contamos com recursos racionais limitados e de que (2) enfrentamos essa limitação fazendo uso de uma especial característica psíquica que nos é inata, notadamente a capacidade de planejar. Mostrei que esses traços são de especial importância porque as soluções de Shapiro para muitas das questões que enfrentou, destacadamente as relativas à normatividade do direito e à racionalidade da decisão judicial, são consectárias da racionalidade do planejamento. Na segunda expus as teses centrais do positivismo shapiriano, com o objeto de evidenciar (1) como elas se relacionam à tese da separação e (2) de que maneira elas dialogam com a racionalidade do planejamento. Também procurei descrever o modelo shapiriano desde uma mirada prática, ao discutir o exemplo do planejamento de um jantar que o autor utiliza para ilustrar como funcionam os planos.

\footnotetext{
${ }^{245}$ PALIN, Michael. Diaries 1969 - 1979. The Python years. New York: Thomas Dunne Books/St. Martin's Press, 2007, p. 104.
} 
No Capítulo III destaquei que a TPD é, em grande medida, um esforço de resolução de problemas detectáveis em outras teorias do direito, especialmente nas de Hart e Dworkin. Discuti parte problemas que Shapiro imputa ao positivismo hartiano e expliquei por quais motivos concluiu pela necessidade de construir um novo modelo de positivismo jurídico. O autor destacou, em Legality três falhas da teoria de Hart. A primeira e a segunda se relacionam com a tese da separação no plano da fundação do direito, enquanto a terceira se refere à prática jurídica. Nesse capítulo tratei das duas primeiras, deixando a terceira para o de $n^{\circ} \mathrm{V}$.

Na primeira seção do capítulo observei que, para Shapiro, Hart não explica a normatividade do direito e portanto não supera o Dilema da Possibilidade. Essa seria a primeira grande limitação do positivismo hartiano. A falha hartiana se manifesta de duas maneiras. Em primeiro lugar, Hart comete um erro filosófico importante ao considerar que regras e práticas sociais pertenceriam a uma mesma categoria metafísica. Tal circunstância o impede de explicar a origem das regras sociais, particularmente da regra de reconhecimento. Em segundo lugar, a tentativa de superar essa questão pela invocação da ideia de convenções coordenativas lewisianas não é bem sucedida porque não é possível garantir que as prática sociais relevantes para a construção de Hart são de fato convenções dessa espécie. Logo depois mostrei que Shapiro entende que Hart é vencido pelo Desafio de Hume, já que, na teoria hartiana, nada impede que um homem mau possa compreender e descrever o direito normativamente, ainda que não aceite as regras jurídicas do ponto de vista interno. Essa seria a segunda insuficiência relevante do positivismo hartiano.

Na seção subsequente mostrei como Shapiro procurou resolver as insuficiências do modelo hartiano relativamente ao Dilema da Possibilidade com recurso à ideia de planos compartilhados, que seriam naturalmente capazes de gerar normatividade porque decorrentes das normas da racionalidade instrumental, e que seriam superiores tanto às convenções lewisianas quanto às puramente humeanas.

Já na seção de $n^{o} 3$ discuti a solução shapiriana para o Desafio de Hume. Shapiro entende que pode resolvê-lo reconhecendo que o direito possui uma normatividade interna descritível por um observador, de sorte que afirmações sobre o conteúdo do direito são extrações de julgamentos descritivos a partir de fatos também descritivos. 
Ao longo dessas três seções sublinhei como as ideias de Shapiro (1) são inteiramente dependentes da racionalidade do planejamento e (2) redundam na redução da razão prática a uma razão meramente instrumental. Também acentuei como essas posições do autor o vinculam a um caso particular de convencionalismo.

O Capítulo IV foi dedicado à defesa do argumento de que o positivismo dos planos é uma vertente específica de convencionalismo jurídico, que, apesar de estar marcada por certas especificidades, principalmente por sua ligação com racionalidade do planejamento, está suscetível a dois argumentos críticos que atingem o convencionalismo em geral, e que desafiam a ideia de que a tese da separação faria sentido na esfera da fundação do direito.

Uma dessas críticas é a de Dickson. Em suma, ela observa que o convencionalismo aparece no Pós-escrito de Hart como um esforço mal sucedido, desenvolvido em resposta a críticas de Dworkin, de explicar de qual maneira a regra de reconhecimento pode dar aos oficiais de um sistema jurídico razões para aceitá-la como obrigatória. Para a autora, Hart deveria ter se incumbido de teorizar sobre essas razões, em vez de fazer uso da ideia de convenção, que as explica somente em pequena parte. A outra é a de Rodriguez-Blanco, que afirma que o Dilema da Possibilidade só pode ser vencido em conjunto com seu correspondente Dilema Moral, consistente em se saber qual justificação moral existe para a autoridade do direito. Eu a empreguei como complementação da crítica anterior, afirmando que as razões cobradas pela primeira são razões morais.

A união desses dois argumentos, ao meu ver, vence o convencionalismo de Shapiro e mostra que sua teoria é insubsistente em função de sua forte vinculação à tese da separação. Tentei expor como é insuficiente para o autor invocar as normas da racionalidade instrumental para afastar a necessidade de deliberação moral nesse aspecto, destacando que o próprio Bratman, como observam Celano e Canale, reconheceu que os planos podem ter justificações profundas, conectadas a conceitos de moralidade política. Além disso, esclareci que afirmar que as normas da racionalidade instrumental asseguram a normatividade do plano-mestre, como Shapiro tenta fazer, cria para ele uma sensível dificuldade, que é a de vencer a objeção de que a racionalidade instrumental, em si mesma, não pode ser fonte de razões para ação.

A primeira seção desse capítulo voltou-se a oferecer a posição de Dickson. Na seção subsequente o mesmo foi feito relativamente a Rodriguez-Blanco. Já na terceira de 
suas seções destaquei como a união de ambas as correntes argumentativas anteriormente tratadas demonstra que a racionalidade dos planos não consegue esclarecer a normatividade do direito - e que essa visão é partilhada por Bratman, de quem Shapiro importou toda a sua parafernália teórica. Após revisitar o exemplo do jantar shapiriano, concluí que seu convencionalismo não explica essa questão, e que suas falhas revelam como direito exige uma concepção de razão prática necessariamente relacionada a valores. Dito de outro modo, demanda-se o abandono da tese da separação em seu corte fundacional, pois a própria identificação do direito, na condição de sistema normativo, depende de deliberação moral, mesmo que ele seja compreendido como um mero instrumento de planejamento social.

Em seguida, no Capítulo V, destaquei que a prática jurídica é, por excelência, o locus de averiguação da capacidade explicativa de uma teoria do direito, lançando à TPD os olhos da fenomenologia da decisão judicial. Foi nesse ponto que teve relevo a discussão da terceira incapacidade imputada por Shapiro à teoria de Hart, notadamente a de dar conta dos desacordos teóricos que se desenvolvem em nossa prática jurídica. Esse fenômeno é usado por Dworkin para criticar as assim chamadas teorias semânticas e arquimedianas do direito, dentre as quais se inclui o positivismo hartiano.

Narrei como Shapiro aceita a crítica de Dworkin e reconhece que o positivismo não está aparelho para vencê-la, e também descrevi como a TPD foi construída como uma espécie de resposta à posição dworkiniana. Procurei também mostrar que Shapiro tem a intenção de nos convencer de que o positivismo dos planos é superior ao de Hart, e que não somente explica os desacordos teóricos, como oferece uma teoria da interpretação jurídica mais adequada do que a de Dworkin.

O capítulo foi estruturado em quatro seções. A primeira se prestou a dar relevo à natureza da crítica dworkiniana contra o positivismo e a assinalar, sobretudo, que o argumento dos desacordos teóricos tem caráter gramatical. A segunda serviu de palco para uma reconstrução do argumento de Dworkin, conforme delineado no primeiro capítulo de $O$ império do direito. A terceira, de seu turno, foi consagrada a expor os argumentos que Shapiro estrutura para vencer a crítica: ele defende a ideia de que os desacordos teóricos recaem sobre metodologias interpretativas. Discuti os principais componentes dessa explicação e demonstrei que ela se harmoniza com a tese da separação e com a 
racionalidade dos planos. Por fim, na quarta seção, critiquei a resposta de Shapiro a Dworkin, pontuando que ele sequer compreendeu bem aquilo que se propôs a responder, e observando que a análise de seus próprios argumentos revela que mesmo no âmbito da TPD a decisão judicial requer deliberação moral. Após rememorar, pela última vez, o jantar de Shapiro, concluí que a tese da separação não é sustentável no plano da prática jurídica, bem como que a racionalidade da decisão, moralmente carregada, não é a dos planos.

Trilhado esse percurso, concluí que é mal sucedida a tentativa de salvar a tese da separação, e com ela o positivismo jurídico de tradição hartiana, a partir dos planos e da racionalidade do planejamento. A crítica do empreendimento teórico de Shapiro parece demonstrar que devemos abandonar a insistência dos positivistas nesse tipo de projeto explicativo. Ele se debruçou sobre temas clássicos, apresentou ideias sofisticadas acerca deles, ainda no interior da tradição positivista, e mesmo assim não logrou vencer os desafios apontados nestas páginas. Mas isso significaria que nada há de relevante a ser extraído de sua contribuição à filosofia do direito? Penso que não.

A notável sofisticação da teoria do direito de Shapiro mostra com muita clareza o quão profícuo (e necessário) é o engajamento do filósofo do direito em ramos mais gerais da filosofia, em especial na filosofia contemporânea da ação. Ao explicitamente construir a TPD ao redor de uma específica concepção do agir humano e da racionalidade que a qualifica o autor se distanciou de uma série de outros teóricos positivistas que operam com concepções pressupostas, não expressamente defendidas e muitas vezes problemáticas de ação ${ }^{246}$.

Talvez seja viável dizer que o conflito entre positivistas e não-positivistas pode mesmo ser compreendido também como uma disputa em torno de diferentes posições precisamente nesse campo (o que pretendo discutir em nova pesquisa): eles divergem a respeito da ação. Legality traz esse assunto para o centro do debate contemporâneo - e a

\footnotetext{
${ }^{246}$ Esse é o mote da crítica que Veronica Rodriguez-Blanco e Pilar Zambrano dirigem ao positivismo de John Gardner, que, segundo elas, pressupõe uma concepção de ação indefensável (RODRIGUEZ-BLANCO, Veronica, ZAMBRANO, Pilar. One myth of the classical natural law theory: reflecting on the "thin" view of legal positivism. Ratio Juris, Vol. 31, No. 1, March 2018, pp. 9-32). A importância de se levar a sério o significado e a justificação de nossas ações no campo da teoria do direito foi objeto das preocupações de José Reinaldo de Lima Lopes LOPES, José Reinaldo de Lima. Entre a teoria da norma e a teoria da ação. In: STORCK, Alfredo Carlos; LISBOA, Wladimir Barreto. (Org.). Norma, moralidade e interpretação: temas de filosofia política e direito. Porto Alegre: Linus Editores, 2009, v. 1, pp. 43-80).
} 
obra merece encômios por conta disso, muito embora Shapiro não tenha sido o primeiro teórico a palmilhar esse caminho ${ }^{247}$.

Mas não é só. Há mais frutos a colher da árvore da TPD.

O estudo do direito em conexão com a ideia de planificação não é novo e já foi objeto das intuições de diversos autores - dentre eles Miguel Reale, que escreveu sobre o assunto em $1973^{248}$. Shapiro apresentou uma profunda análise de como pode ser o funcionamento das normas e do sistema jurídico compreendidos à luz dos planos, e seus insights, ainda que não se constituam em uma boa explicação para o direito como um todo, podem ser úteis e proveitosos relativamente a determinados ramos do direito e a certos institutos com os quais lidamos na prática jurídica - principalmente se a sua utilização estiver justificada em princípios que recomendem sua aplicação nesses $\operatorname{casos}^{249}$. Já há alguns escritos sobre o tema, os quais demonstram, por exemplo, que a obra de Shapiro é capaz de gerar dividendos importantes para a teoria dos $\operatorname{contratos}^{250}$, para a teoria da revisão judicial de atos administrativos, para a solução de conflitos jurídicos do cotidiano forense $^{251}$ e para o uso de precedentes pelos tribunais ${ }^{252}$. Nada impede, por outro lado, que legisladores encampem a racionalidade dos planos ao divisarem diplomas legais complexos a respeito de temas os mais diversos. Particularmente interessante seria a possibilidade de normas dessa espécie que contassem com uma parte geral alinhada à racionalidade do planejamento, mas justificada em posições normativas substantivas. A própria ideia de planejamento, então, trazida para o âmbito da teoria do direito, se constitui em um importante dividendo do engajamento na obra shapiriana.

\footnotetext{
${ }^{247}$ Coleman já o fizera (COLEMAN, 2001).

${ }^{248}$ REALE, Miguel. Direito e planificação. In: CLÉVE, Clêmerson Merlin, BARROSO, Luís Roberto (organizadores). Direito constitucional. Doutrinas essenciais. Vol. VI. Constituição financeira, econômica e social. São Paulo: Thomson Reuters/Revista dos Tribunais, 2011, pp. 739-744.

${ }^{249}$ Isso, inclusive, parece compatível com teorias do direito de cunho dworkiniano, uma vez que Dworkin admite, pela via da ideia de prioridade local, que alguns ramos do direito podem exigir do intérprete que se vincule a interpretações mais literais do direito. Isso pode ocorrer, por exemplo, no direito dos registros públicos e no direito penal.

${ }^{250}$ BRIDGEMAN, Curtis. Contracts as plans. University of Illinois Law Review, Vol. 2009, No. 2, 2009, pp. 341-402; SHEEHAN, Duncan. Mistake, failure of consideration and the planning theory of intention. Canadian Journal of Law \& Jurisprudence, Volume28, Issue 01, January 2015, pp. 155-181.

${ }^{251}$ Cf. BRASIL, 2017, comentada na introdução.

252 FORTES, Luiz Henrique Krassuski. Justificação dos precedentes: direito como planejamento, poder judiciário e motivação a partir do precedente. 2015. 188 f. Dissertação (Mestrado em Direito) - Setor de Ciências Jurídicas, Universidade Federal do Paraná, Curitiba, 2015.
} 
Parece especialmente relevante, no entanto, a discussão que o autor desenvolve em torno da ideia de confiança. É verdade que a aplicabilidade irrestrita do conceito aos juízes talvez mereça ser encarada com certo ceticismo, uma vez que a atividade que eles desempenham soa incompatível com a conclusão de que o legislador constituinte não confia neles - principalmente quando se observa que, na acepção positivista da decisão judicial, eles sempre têm liberdade para decidir discricionariamente nos casos que acima denominei “(D3)" e "(D4)”. Ainda assim, quando se pensa no funcionalismo público em sentido mais geral, a invocação de uma economia da confiança presente nas normas fundamentais do ordenamento jurídico e identificável pelos próprios servidores diante das demandas atinentes às suas funções pode auxiliar no entendimento dos limites impostos à atuação de cada um - particularmente na prática de atos administrativos de cunho discricionário. Isso pode ter reflexos na eficiência do serviço público, na resolução de conflitos com particulares e até mesmo no campo disciplinar. Além disso, e por outro lado, a confiança, como valor político-moral, pode se consubstanciar em um interessante ponto de saída para uma teoria normativa que indique que o funcionamento da prática jurídica seja aquele recomendado pelo positivismo exclusivista.

Apesar de falhar enquanto defesa definitiva de um positivismo jurídico mais radical em sua relação com a moral, o livro de Shapiro nos aparelha, ademais, - e aqui parafraseio Waldron - com uma nova fonte de analogias explicativas para o enfrentamento das perenes questões da filosofia do direito e da prática jurídica. Tudo indica que, nos próximos anos, mais e mais usos dessa fonte serão descobertos e explorados. Ao menos o plano parece ser esse. 


\section{REFERÊNCIAS}

ALEXANDER, Larry. The gap. Harvard Journal of Law \& Public Policy, Vol. 14, N. 3, 1991, pp. 695-701.

. Can law survive the asymmetry of authority? QLR, Volume 19, Number 3, 2000, pp. 463-481.

ALEXY, Robert. Scott J. Shapiro between Positivism and Non-Positivism. Jurisprudence, 7:2, 2016, pp. 299-306.

ANSCOMBE, G.E.M. On the source of the authority of the state. In:

Ethics, religion and politics: collected philosophical papers, v. 3. Oxford: Basil Blackwell, 1981, pp. 130-155.

BAER, Judith. Legality, by Scott J. Shapiro. Political Science Quarterly. Vol. 126, Issue 4, Winter 2011, pp. 696-697.

BAND, Jeffrey. Shapiro's Legality. Journal of Moral Philosophy, Vol. 12, 2015, pp. 83102.

BERTEA, Stefano. Law, shared activities, and obligation. Canadian Journal of Law and Jurisprudence, Vol. XXVII, No. 2, July 2014, pp. 357-381.

BIX, Brian. Legality, by Scott J. Shapiro. Ethics, Volume 122, Number 2, January 2012, pp. 444-448.

BRASIL. $2^{\text {a }}$ Vara Federal Cível da Subseção Judiciária da Capital do Estado de São Paulo. Ação $n^{\circ}$ 0008950-50.2016.403.6100, São Paulo, SP, 20 de fevereiro de 2017. Disponível em <http://web.trf3.jus.br/diario/Consulta/BaixarPdf/15330>. Acesso em 20/12/2017.

BRASIL. Supremo Tribunal Federal. Ação Direta de Inconstitucionalidade $n^{\circ} 4277$, Brasília, DF, 5 de maio de 2011. Disponível em <http://www.stf.jus.br/portal/geral/verPdfPaginado.asp?id=400547\&tipo=TP\&descricao= ADI\%2F4277>. Acesso em 20/12/2017. 
BRASIL. Supremo Tribunal Federal. Arguição de Descumprimento de Preceito Fundamental $\mathrm{n}^{\mathrm{o}}$ 132, Brasília, DF, 5 de maio de 2011. Disponível em $<$ http://redir.stf.jus.br/paginadorpub/paginador.jsp?docTP=AC\&docID=628633>. Acesso em 20/12/2017.

BRASIL. Supremo Tribunal Federal. Arguição de Descumprimento de Preceito Fundamental $\mathrm{n}^{\mathrm{o}}$ 54, Brasília, DF, 12 de abril de 2012. Disponível em $<$ http://redir.stf.jus.br/paginadorpub/paginador.jsp?docTP=TP\&docID=3707334>. Acesso em 20/12/2017.

BRATMAN, Michael. Intention, plans, and practical reason. Cambridge/London: Harvard University Press, 1987.

. Taking plans seriously. In: MILLGRAM, Elijah. Varieties of practical reasoning. London/Cambridge: The MIT Press, 2001, pp. 203-220.

Reflections on law, normativity, and plans. In: BERTEA, Stefano, PAVLAKOS, George (Eds.). New essays on the normativity of law. Oxford: Hart Publishing, 2011, pp. 73-85.

. Shared agency. A planning theory of acting together. New York: Oxford University Press, 2014.

BRIDGEMAN, Curtis. Contracts as plans. University of Illinois Law Review, Vol. 2009, No. 2, 2009, pp. 341-402.

BROOME, John. Does rationality give us reasons? Philosophical Issues, 12, Normativity, 2005, pp.321-337.

BUSTAMANTE, Thomas. Interpreting plans. Australian Journal of Legal Philosophy. Vol. 37, 2012a, pp. 219-250.

Legality, by Scott Shapiro. Legal Studies. Vol. 32, No. 3, September 2012b, pp. 499-522. 
A breve história do positivismo descritivo. O que resta do positivismo jurídico depois de H. L. A. Hart? Revista Novos Estudos Jurídicos. Vol. 20. N 1. Jan-Abr 2015, pp. 307-327.

BUSTAMANTE, Thomas; CUNHA, Mirlir. Muito além do plano: objeções à visão de direito de Scott $\quad$ Shapiro. $2013 . \quad$ Disponível em <http://www.publicadireito.com.br/artigos/?cod=8386fa112ba70c3f $>$. Acesso em 20/04/2014.

CAMPBELL, Tom. Rewriting Hart's Postscript: thoughts on the development of legal positivism. Problema: Anuario de Filosofia y Teoria del Derecho, núm. 5, 2011, pp. 23-52.

CANALE, Damiano. Looking for the nature of law: on Shapiro's Challenge. In: CANALE, Damiano; TUZET, Giovanni (Eds). The planning theory of law. A critical reading. Dordrecht/Heidelberg/New York/London: Springer, 2013, pp. 1-26.

CELANO, Bruno. Law, plans and practical rationality. Diritto \& Questioni Pubbliche. N. 12, 2012b, pp. 211-254.

COELHO, André Luiz Souza. Por que surgem as regras secundárias? Uma reinterpretação da fábula de Hart. Revista da Faculdade de Direito da UERJ - RFD, v. 1, n. 25, 2014a. Disponível em <http://www.e-publicacoes.uerj.br/index.php/rfduerj/article/view/11661>. Acesso em 10/10/2016

. Dworkin e Gadamer: qual conexão? PERI, V. 06, n. 01, 2014b, pp. 19-43.

Disponível em <http://nexos.ufsc.br/index.php/peri/article/view/905>. Acesso em $18 / 9 / 2016$.

COLEMAN, Jules. The practice of principle: in defense of a pragmatist approach to legal theory. Oxford: Oxford University, 2001.

. The architecture of jurisprudence. The Yale Law Journal, 121:2, 2012, pp. $2-80$.

CRANE, Stephen. Prose and poetry. New York: The Library of America, 1984. 
CROCKER, Lawrence. The power of positive planning. Analysis Reviews. Vol. 72, No. 3, July 2012, pp. 541-551.

CROCKER, Thomas P. Whom should you trust? Plans, pragmatism, and legality. Tulsa Law Review. Vol. 47, 2011, pp. 205-217.

DICKSON, Julie. Is the rule of recognition really a conventional rule? Oxford Journal of Legal Studies, Vol. 27, No.3, 2007, pp. 373-402.

DRUMMOND DE ANDRADE, Carlos. O avesso das coisas, São Paulo: Record, 1987.

DUARTE D'ALMEIDA, Luís. The grounds of law. In: WALUCHOW, Wil. SCIARAFFA, Stefan (editors). The legacy of Ronald Dworkin. Oxford: Oxford University Press, 2016, pp. 165-202.

DUKE, George. The planning theory and natural law. Law and Philosophy: pp. 1-28. Published Online: 14 July 2014. Disponível em <http://link.springer.com/article/10.1007/s10982-014-9213-x>. Acesso em 15/11/2014.

DYZENHAUS, David. Legality without the rule of law? Scot Shapiro on wicked legal systems. Critical notice: Legality, by Scott Shapiro. Canadian Journal of Law and Jurisprudence. Vol. XXV. No. 1. January 2012, pp. 183-200.

DWORKIN, Ronald. Taking rights seriously. Cambridge: Harvard University Press, 1977. Law's empire. Cambridge/London: The Belknap Press of Harvard University Press, 1986. . Legal theory and the problem of sense. In: HART, H. L. A.; GAVISON, Ruth. Issues in contemporary legal philosophy: the influence of H. L. A. Hart. Oxford: Oxford University Press, 1987, pp. 9-20.

. Uma questão de princípio. Traduzido por Luís Carlos Borges. São Paulo: Martins Fontes, 2001. . Levando os direitos a sério. Traduzido por Nelson Boeira. São Paulo: Martins Fontes, 2002. 
. Justice in robes. Cambridge/London: The Belknap Press of Harvard University Press, 2006.

. Can we disagree about law or morals? In: Launch of the NYIP, New York Institute of Philosophy, New York University, New York, 2007. Disponível em $<$ http://www.thirteen.org/forum/topics/can-we-disagree-about-law-or-morals/14/>. Acesso em $18 / 3 / 2015$

. Justice for hedgehogs. Cambridge/London: The Belknap Press of Harvard University Press, 2011.

. O império do direito. $3^{\text {a }}$ Edição. Traduzido por Jeferson Luiz Camargo. São Paulo: Martins Fontes, 2014.

EDMUNDSON, William. Shmegality. Georgia State University College of Law. Legal Studies Research Paper No. 2012-02. 2011. Disponível em <http://ssrn.com/abstract=1835746>. Acesso em 05/05/2014.

ESSERT, Christian. Legal obligation and reasons. Legal Theory. 19, 2013, pp. 63-88.

FAGGION, Andréa Luisa Bucchile. O problema da legitimidade da autoridade política, ou sobre o que diferencia o estado da máfia. Philósophos, Goiânia, V. 22, N. 2, Jul/Dez 2017, pp. 37-79.

FARRELL, Ian P. On the value of jurisprudence. Legality, by Scott J. Shapiro. Texas Law Review. Vol. 90, 2011, pp. 187-224.

FORTES, Luiz Henrique Krassuski. Justificação dos precedentes: direito como planejamento, poder judiciário e motivação a partir do precedente. 2015. 188 f. Dissertação (Mestrado em Direito) - Setor de Ciências Jurídicas, Universidade Federal do Paraná, Curitiba, 2015.

FULLER, Lon L. The morality of law. New Haven: Yale University Press, 1969. 
GARCIA, Edgar Ramón Aguilera. La naturaleza del derecho: Están nuestras prácticas jurídicas fundadas en una convención constitutiva o en un plan compartido? Alegatos, Núm. 81, mayo/agosto 2012, pp. 347-372.

GARDNER, John. Legal positivism: 5 1 12 myths. The American Journal of Jurisprudence. Vol. 46, 2001, pp. 199-227.

GARDNER, John; MACKLEM, Timothy. Scott J. Shapiro. Legality. Notre Dame Philosophical Reviews. 2011. Disponível em <http://ndpr.nd.edu/news/27609-legality/>. Acesso em 27/03/2014.

GOULART, André Coletto Pedroso. A discricionariedade judicial no debate HartDworkin. 2015. 87 f. Tese de Láurea (Graduação em Direito) - Faculdade de Direito, Universidade de São Paulo, São Paulo, 2015.

GREEN, Leslie. Positivism and conventionalism. Canadian Journal of Law and Jurisprudence, Vol. XII, No. 1, January 1999, pp. 35-52.

Are there any 'theoretical disagreements' about law? Disponível em <https://ljmgreen.com/2016/08/29/are-there-any-theoretical-disgreements-about-law/>. Acesso em 30/8/2016.

GREEN, Michael S. On Hart's category mistake. Legal Theory. Vol. 19, 2013 pp.347-369.

GUEST, Stephen. Ronald Dworkin. Stanford: Stanford University Press, 2012. GLOP, The moral aim of the law and trusting judges. Analysis Reviews, Vol. 72, Number 3, July 2012a, pp. 552-563.

HACKER, P.M.S. Wittgenstein's place in Twentieth-Century analytic philosophy. Oxford: Blackwell Publishers, 1996.

HART, H. L. A. The concept of law. Second Edition. Oxford: Clarendon Press, 1994. O conceito de direito. Traduzido por A. Ribeiro Mendes. Lisboa: Fundação Calouste Gulbenkian, 2001. 
HERSHOVITZ, Scott. The model of plans and the prospects for positivism. Public Law and Legal Theory Research Series. Paper no. 354. September 2013. Disponível em < http://ssrn.com/abstract=2322457> . Acesso em 16/09/2014.

HOLTON, Richard. Willing, wanting, waiting. Oxford: Clarendon Press, 2009.

HOWARTH, David, STARK, Shona Wilson. H. L. A. Hart's secondary rules: what do 'officials' really think? International Journal of Law in Context, 14 (1), 2018, pp. 61-86.

HUME, David. A treatise of human nature. Vol. 1. Edited by David Fate Norton and Mary J. Norton. Oxford: Clarendon Press, 2007.

IBSEN, Henryk. Lyrical poems. Selected and translated by R. A. Streatfeild. London: Elkin Matthews/Vigo Street, 1902.

KORSGAARD, Christine M. The constitution of agency. Oxford: Oxford University Press, 2008.

KOZICKI, Katya. Herbert Hart e o positivismo jurídico. Textura aberta do direito e discricionariedade judicial. Curitiba: Juruá Editora, 2014.

LARKIN, Phillip. The complete poems. Edited by Archie Burnett. London: Faber and Faber, 2014.

LEITER, Brian. The end of empire: Dworkin and jurisprudence in the 21 st Century. Rutgers Law Journal. Vol. 36, 2004, pp. 165-181.

. Explaining theoretical disagreement. The University of Chicago Law Review. Vol. 76, 2009, pp. 1215-1250.

. Theoretical disagreements in law: another look. Disponível em $<$ https://ssrn.com/abstract=2830732>. Acesso em 15/09/2016.

LEWIS, David. Convention. A philosophical study. Oxford: Blackwell Publishers, 2002. 
LOPES, José Reinaldo de Lima. Entre a teoria da norma e a teoria da ação. In: STORCK, Alfredo Carlos; LISBOA, Wladimir Barreto. (Org.). Norma, moralidade e interpretação: temas de filosofia política e direito. Porto Alegre: Linus Editores, 2009, v. 1, pp. 43-80.

MACEDO JUNIOR, Ronaldo Porto. O direito em desacordo. O debate entre o interpretativismo e o convencionalismo jurídico. 2013. 247 f. Tese (Concurso de Professor Titular) - Faculdade de Direito, Universidade de São Paulo, São Paulo, 2013a.

. Do xadrez à cortesia. Dworkin e a teoria do direito contemporânea. São Paulo: Saraiva, 2013b.

MARANHÃO, Juliano. Positivismo jurídico lógico-inclusivo. São Paulo: Marcial Pons, 2012.

MARMOR, Andrei. Interpretation and legal theory. Oxford/Portland: Hart Publishing, 2005.

MELERO DE LA TORRE, Mariano C. Recensión. Legality, Scott J. Shapiro. Eunomía. Revista en Cultura de la Legalidad. No. 2, Marzo - Agosto 2012, pp. 227-233.

MERWIN, W. S. The second four books of poems .Port Townsend, WA: Copper Canyon Press, 1993.

MICHELON JR., Cláudio Fortunato. Aceitação e objetividade. Uma comparação entre as teses de Hart e do positivismo precedente sobre a linguagem e o conhecimento do direito. São Paulo: RT, 2004.

MURPHY, Mark C. Book review. Scott J. Shapiro. Legality. Law and Philosophy. Vol. 30, Issue 3, May 2011, pp. 369-375.

No more fresh starts. Analysis Reviews. Vol. 72, No. 3, 2012, pp. 563573.

NEIVA, Horário Lopes Mousinho. Teoria do direito e análise conceitual: uma crítica à metodologia de Scott J. Shapiro. Revista da Faculdade de Direito da UFMG, Belo Horizonte, n. 65, jul./dez. 2014, pp. 261-284. 
.Meta-teoria do direito. Ensaios reunidos. Porto Alegre: Editora Fi, 2017.

PALIN, Michael. Diaries 1969 - 1979. The Python years. New York: Thomas Dunne Books/St. Martin's Press, 2007.

PAPAYANNIS, Diego M. Legality: Between purposes and functions. University of Girona. Legal Theory and Philosophy. Working Paper Series. No. 20. Disponível em <https://www.academia.edu/6011217/Legality_Between_Purposes_and_Functions>. Acesso em 27/03/2014.

PATTERSON, Dennis. Explicating the internal point of view. SMU Law Review, No. 52, 1999, pp. 67-74.

PICCOLO, Carla Henriete Bevilacqua. A moral e o conceito de direito em H. L.A. Hart. 2011. 129 f. Dissertação (Mestrado em Direito) - Faculdade de Direito, Universidade de São Paulo, São Paulo, 2011.

PLUNKETT, David. Legal positivism and the moral aim thesis. Oxford Journal of Legal Studies. Vol. 33 (3), Autumn 2013a, pp. 563-605.

. The Planning Theory of Law I: the nature of legal institutions. Philosophy Compass. Vol. 8/2, 2013b, pp. 149-158.

. The Planning Theory of Law II: the nature of legal norms. Philosophy Compass. Vol. 8/2, 2013c, pp. 159-169.

PLUNKETT, David, SHAPIRO, Scott. Law, morality, and everything else: general jurisprudence as a branch of metanormative inquiry. Ethics, 128, October 2017, pp. 37-68.

POSTEMA, Gerald J. Bentham. Coordination and convention at the foundations of law. The Journal of Legal Studies. Vol. 11, No. 1, January 1982, pp. 165-203.

. Norms, reasons, and law. Current Legal Problems, Volume 51, Issue 1, 1 January 1998, pp. 149-179. 
. Legal philosophy in the Twentieth Century: The common law world (A Treatise of Legal Philosophy and General Jurisprudence, Vol. 11). Dordrecht/Heidelberg/New York/London: Springer, 2011.

PULIDO, Carlos Bernal. Austin, Hart e Shapiro: três concepções sobre o direito como entidade fundada em uma prática social. Tradução de Thomas da Rosa de Bustamante. Revista Brasileira de Estudos Políticos. No. 307, Julho/Dezembro de 2013, pp. 43-98.

RAZ, Joseph. Postscript to Legal principles and the limits of the law. In: COHEN, Marshall (Ed.). Ronald Dworkin and contemporary jurisprudence. Totowa: Rowman \& Allanheld, 1983, pp. 84-85

. Two views of the nature of the theory of law: a partial comparison. Legal Theory, Volume 4, Issue 03, September 1998, pp. 249-282.

REALE, Miguel. Direito e planificação. In: CLÉVE, Clêmerson Merlin, BARROSO, Luís Roberto (organizadores). Direito constitucional. Doutrinas essenciais. Vol. VI. Constituição financeira, econômica e social. São Paulo: Thomson Reuters/Revista dos Tribunais, 2011, pp. 739-744.

RIPSTEIN, Arthur. Introduction: Anti-Archimedianism. In: RIPSTEIN, Arthur (Ed.). Ronald Dworkin. Cambridge: Cambridge University Press, 2007, pp. 1-21

. Self-certification and the moral aims of the law. Critical notice: Legality, by Scott Shapiro. Canadian Journal of Law and Jurisprudence, Vol. XXV, No. 1, January 2012, pp. 201-2017.

RODRIGUEZ-BLANCO, Veronica. The moral puzzle of legal authority. A commentary on Shapiro's Planning Theory of Law. In: BERTEA, Stefano; PAVLAKOS, George (editors). New essays on the normativity of law. Oxford and Portland, Oregon, 2011, pp. 86-106.

RODRIGUEZ-BLANCO, Veronica, ZAMBRANO, Pilar. One myth of the classical natural law theory: reflecting on the "thin" view of legal positivism. Ratio Juris, Vol. 31, No. 1, March 2018, pp. 9-32. 
ROSATI, Connie S. Normativity and the Planning Theory of Law. Jurisprudence, 7:2, 2016, pp. 307-324.

RUNDLE, Kristen. Forms liberate. Reclaiming the jurisprudence of Lon L. Fuller. Oxford: Hart Publishing, 2012.

RYAN, Kay. The best of it. New and selected poems. New York: Grove Press, 2010.

SCHAUER, Frederick. Playing by the Rules. A Philosophical Examination of Rule-Based Decision Making in Law and in Life. Oxford: Clarendon Press, 1991, reprinted in 2002.

. The best laid plans. Review of Scott Shapiro's Legality. The Yale Law Journal. Vol. 120, 2010, pp. 586-621.

SEARLE, John. How to derive an ought from an is. The Philosophical Review, No. 73, January 1964, pp. 43-58.

SHAPIRO, Scott. On Hart's way out. Legal Theory. Vol. 4, Issue 4, December 1998, pp. 469-507.

. Was inclusive legal positivism found on a mistake? Ratio Juris, Volume 22, Number 3, September 1999, pp. 326-338.

. Law, plans, and practical reason. Legal Theory. Vol. 8, 2002a, pp. 387441.

. Authority. In: COLEMAN, Jules; SHAPIRO, Scott. The Oxford handbook of jurisprudence \& philosophy of law. Oxford: Oxford University Press, 2002b, pp. 383439

. What is the internal point of view? Fordham Law Review, Volume 75, Issue 3, 2006, pp. 1157-1170.

. The Hart-Dworkin debate: a short guide for the perplexed. In: RIPSTEIN, Arthur (editor). Ronald Dworkin. Cambridge: Cambridge University Press, 2007, pp. 2255. 
. What is the rule of recognition (and does it exist)? In: ADLER, Matthew D., HIMMA, Kenneth Einar (editors). The rule of recognition and the U.S. Constitution. Oxford: Oxford University Press, 2009, pp. 235-268.

. Legality. London/Cambridge: The Belknap Press of Harvard University Press, 2011.

. Summary. Book Symposium. Legality, by Scott J. Shapiro. Analysis Reviews. Vol. 72, No. 3, July 2012, pp. 537-541.

. Reply to Crocker, Guest and Murphy. Analysis Reviews. Vol. 72, No. 3, July 2012, pp. 573-587.

. Legalidad. Traducción de Diego M. Papayannis y Lorena Ramírez Ludeña. Madrid: Marcial Pons, 2014.

合法性. China: China Legal Publishing House, 2016.

SHEEHAN, Duncan. Mistake, failure of consideration and the planning theory of intention. Canadian Journal of Law \& Jurisprudence, Volume28, Issue 01, January 2015, pp. $155-181$.

SHERWIN, Emily. Legality and rationality: a comment on Scott Shapiro's Legality. Legal Theory. Vol. 19, Special Issue 04, December 2013, pp. 403-421.

SIMMONDS, Nigel E. The logic of planning and the aim of the law. University of Toronto Law Journal. Vol. 62, No. 2, Spring 2012, pp. 255-276.

SMITH, Dale. Theoretical disagreement and the semantic sting. Oxford Journal of Legal Studies. Vol. 30 (4), 2010, pp. 635-661.

SPAAK, Torben. Legal positivism, conventionalism, and the normativity of law. Disponível em < https://ssrn.com/abstract=2978561>. Acesso em 5/6/2017.

STONE, Martin Jay. Planning positivism and planning natural law. Critical notice: Legality, by Scott Shapiro. Canadian Journal of Law and Jurisprudence. Vol. XXV, No. 1, January 2012, pp. 219-235. 
STRAVOPOULOS, Nicos. The debate that never was. Harvard Law Review, Vol. 130, 2017, pp. 2082-2095.

STRECK, Lênio Luiz. Do pamprincipiologismo à concepção hipossuficiente de princípio. Dilemas da crise do direito. Revista de Informação Legislativa, Brasília, a. 49, n. 194, abr/jun 2012, pp. 7-21.

STRUCHINER, Noel. Para falar de regras. 2005. 191 f. Tese (Doutorado em Filosofia) Departamento de Filosofia, Pontifícia Universidade Católica do Rio de Janeiro, Rio de Janeiro, 2005.

O “aparente" paradoxo das regras. Ethic@, Florianópolis, v. 8, n. 3, maio de 2009, pp. 63-71.

TINTURÈ, Maris Kópcke. Positive law's moral purpose(s): towards a new consensus? The American Journal of Jurisprudence, Vol. 56, 2011, pp. 183-214.

$\mathrm{TOH}$, Kevin. Plan-attitudes, plan-contents, and bootstrapping: some thoughts on the Planning Theory of Law. 2013. Disponível em <http://ssrn.com/abstract=2307318>. Acesso em 07/04/2014.

TORRANO, Bruno. Do fato à legalidade. Introdução à teoria analítica do direito. Rio de Janeiro: Lumen Juris, 2014.

TROPER, Michael. Judges taken too seriously: Professor Dworkin's views on jurisprudence. Ratio Juris. Vol. 1, No. 2, July 1998, pp. 162-175.

YAFFE, Gideon. Book review: Legality. Philosophical Review, Vol. 121, No. 3, 2012, pp. 451-474.

WALLACE, R. Jay. Normativity, commitment, and instrumental reason. Philosopher's Imprint, Volume 1, No. 3, December 2001, pp. 1-26.

WALDRON, Jeremy. Planning for legality. Michigan Law Review. Vol. 109, April 2011, pp. 883-902. 
WINCH, Peter. The idea of a social science and its relation to philosophy. Second Edition. London: Routledge, 2008. 